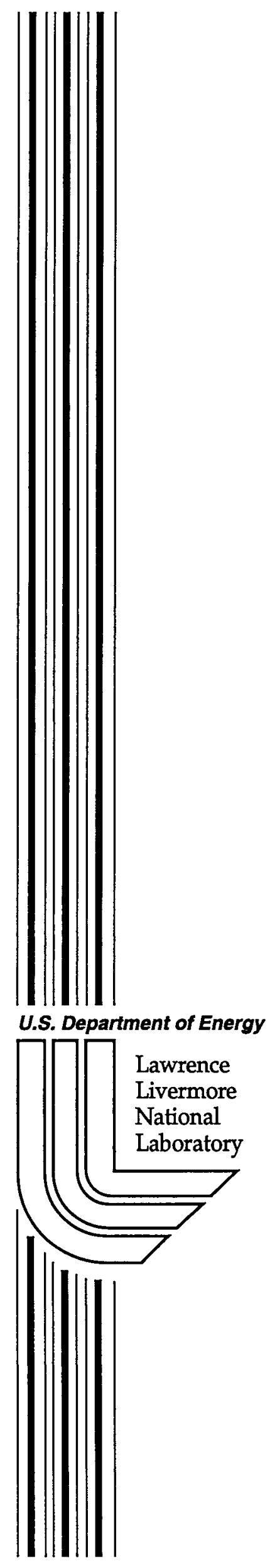

UCRL-ID-148021

\title{
Thick Liquid-Walled Spheromak Magnetic Fusion Power Plant
}

R.W. Moir, R.H. Bulmer, T.K. Fowler, T.D. Rognlien, M.Z. Youssef

\section{April 8, 2002}




\section{DISCLAIMER}

This document was prepared as an account of work sponsored by an agency of the United States Government. Neither the United States Government nor the University of California nor any of their employees, makes any warranty, express or implied, or assumes any legal liability or responsibility for the accuracy, completeness, or usefulness of any information, apparatus, product, or process disclosed, or represents that its use would not infringe privately owned rights. Reference herein to any specific commercial product, process, or service by trade name, trademark, manufacturer, or otherwise, does not necessarily constitute or imply its endorsement, recommendation, or favoring by the United States Government or the University of California. The views and opinions of authors expressed herein do not necessarily state or reflect those of the United States Government or the University of California, and shall not be used for advertising or product endorsement purposes.

This work was performed under the auspices of the U. S. Department of Energy by the University of California, Lawrence Livermore National Laboratory under Contract No. W-7405-Eng-48.

This report has been reproduced directly from the best available copy.

Available electronically at http://www.doc.gov/bridge

Available for a processing fee to U.S. Department of Energy

And its contractors in paper from

U.S. Department of Energy

Office of Scientific and Technical Information

P.O. Box 62

Oak Ridge, TN 37831-0062

Telephone: (865) 576-8401

Facsimile: (865) 576-5728

E-mail: reports@adonis.osti.gov

Available for the sale to the public from

U.S. Department of Commerce

National Technical Information Service

5285 Port Royal Road

Springfield, VA 22161

Telephone: (800) 553-6847

Facsimile: (703) 605-6900

E-mail: orders@ntis.fedworld.gov

Online ordering: http://www.ntis.gov/ordering.htm

OR

Lawrence Livermore National Laboratory

Technical Information Department's Digital Library

http://www.llnl.gov/tid/Library.html 


\title{
Thick liquid-walled spheromak magnetic fusion power plant
}

\author{
R. W. Moir, R. H. Bulmer, T. K. Fowler, T. D. Rognlien, M. Z. Youssef
}

April 8, 2002

\begin{abstract}
We assume a spheromak configuration can be made and sustained by a steady gun current, which injects particles, current and magnetic field, i.e., helicity injection. The equilibrium is calculated with an MHD equilibrium code, where an average beta of $10 \%$ is found. The toroidal current of $40 \mathrm{MA}$ is sustained by an injection current of $100 \mathrm{kA}$ ( $125 \mathrm{MW}$ of gun power). The flux linking the gun is $1 / 1000^{\text {th }}$ that of the flux in the spheromak. The geometry allows a flow of liquid, either molten salt, (flibe- $\mathrm{Li}_{2} \mathrm{BeF}_{4}$ or flinabe- $\mathrm{LiNaBeF}$ ) or liquid metal such as SnLi which protects most of the walls and structures from neutron damage. The free surface between the liquid and the burning plasma is heated by bremsstrahlung and optical radiation : 1 nd neutrons from the plasma. The temperature of the free surface of the liquid is calculated and then the evaporation rate is estimated. The impurity concentration in the burning plasma is estimated and limited to a $20 \%$ reduction in the fusion power. For a high radiating edge plasma, the divertor power density of $460 \mathrm{MW} / \mathrm{m}^{2}$ is handled by high-speed $(20 \mathrm{~m} / \mathrm{s})$, liquid jets. For low radiating edge plasmas, the divertorpower density of $1860 \mathrm{MW} / \mathrm{m}^{2}$ is too high to handle for flibe but possibly acceptable for $\mathrm{SnLi}$ with jets of $100 \mathrm{~m} / \mathrm{s}$ flow speed. Calculations show the tritium breeding is adequate with enriched ${ }^{6} \mathrm{Li}$ and appropriate design of the walls not covered by flowing liquid $15 \%$ of the total). We have come up with a number of problem areas needing further study to make the design self consistent and workable.
\end{abstract}




\section{Table of contents}

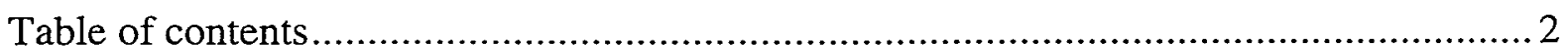

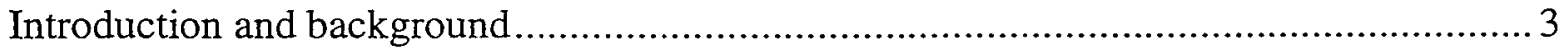

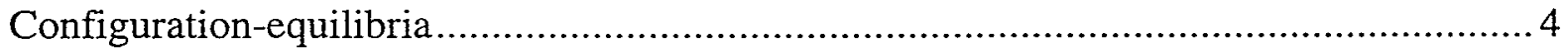

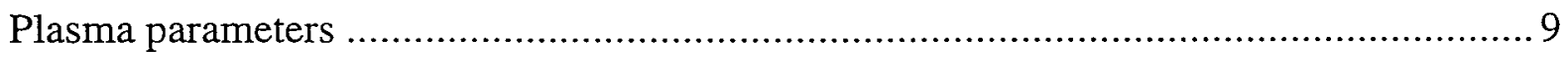

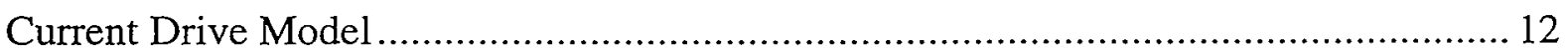

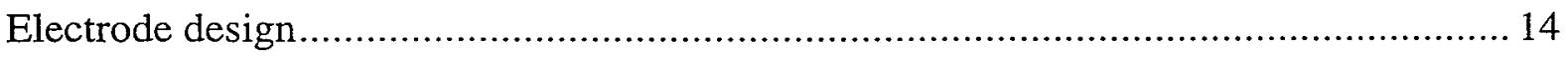

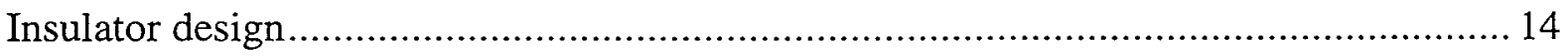

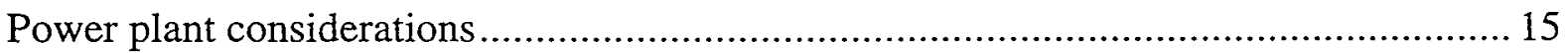

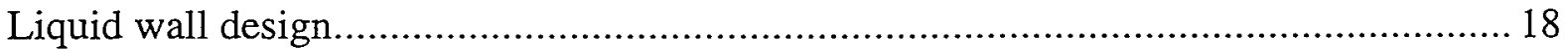

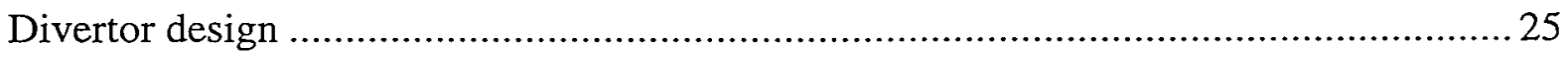

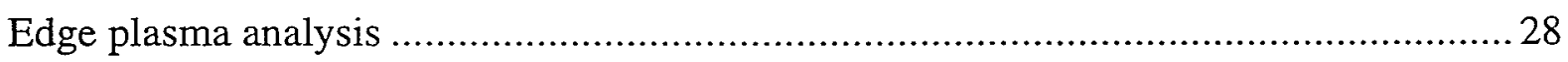

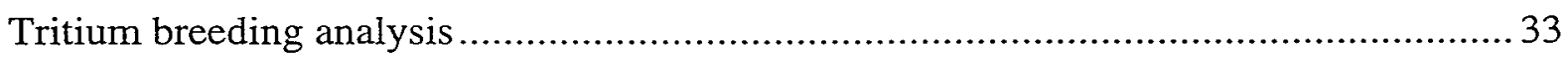

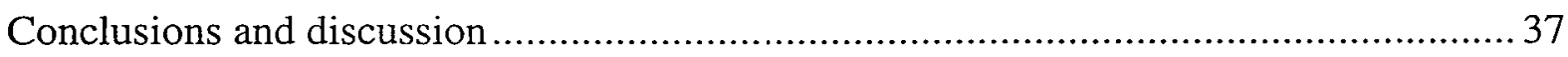

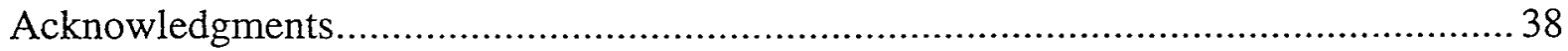

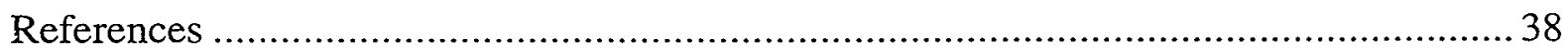




\section{Introduction and background}

This power plant design study applies liquid walls to the steady state spheromak plasma confinement configuration. A self-consistent point design was not achieved in all aspects due to known inconsistencies. These inconsistencies set the agenda for further work.

The spheromak idea came about by a number of routes[1]. The toroidal coils of the tokamak might not be necessary if the plasma could carry enough current in the toroidal direction to make a sufficient toroidal field. In this case, the performance might be tokamak-like with a simpler magnet configuration. Marshall plasma guns made reasonably stable configurations. Early experiments were encouraging. Hagenson and Krakowski made a reactor design [2]. Other reactor studies included solid first walls and boiling liquid blankets [3] and pulsed liquid walls [4]. The main theme of this work is the use of liquid wall and steady state operation.

The logic of this design process follows:

- the configuration is description based on MHD equilibrium calculations

- a disclission of the steady-state gun injection for current drive

- the development of the plasma and other related parameters

- a discussion of the electrodes and insulators

- a discussion of the liquid wall flows with the calculation of surface temperatures (based on incident power on the liquid surface and interior,)

- the calculation of evaporation rates from the liquid surfaces that depend only on surface temperature

- discussion of the edge plasma, the estimates of evaporation allowed from core plasma contamination with impurities, and the ability to breed tritium

We consider low conductivity liquids (molten salts) and high conductivity liquids (liquid metals). The usual molten salt is flibe $\left(\mathrm{Li}_{2} \mathrm{BeF}_{4}\right)$, but past studies 
show the evaporation limits require temperatures near or below the melt temperature of $460^{\circ} \mathrm{C}$. Adding $\mathrm{NaF}$ to flibe produces flinabe $\left(\mathrm{NaF}+\mathrm{LiF}+\mathrm{BeF}_{2}=\right.$ $\mathrm{LiNaBeF}_{4}$ ),[5], whose melt temperature is reduced to $\sim 310^{\circ} \mathrm{C}$. This study is based on flinabe as a candidate molten salt. $\mathrm{SnLi}$ is the liquid metal candidate.

There are many aspects of the design that do not meet requirements or are inconsistent. These are discussed through out the report and many suggestions for further work are made.

\section{Configuration-equilibria}

The spheromak reactor shown in Fig. 1 was developed with the Corsica code. It is an axi-symmetric configuration with a nearly up/down symmetric confined region, but with slight vertical asymmetry to provide a single (lower) divertor. The shape of the confined region is maintained with 6 circular coils arranged in an up/down symmetric fashion. Two additional coils channel diverted flux around the gun electrodes and into a collector region. The free-boundary equilibrium is designed to have a flux amplification factor of 1000 with an elongation less than 2 to mitigate instabilities. Of particular concern are tilt and shift modes which will probably require [6] active feedback coils. These coils are envisioned to be relatively small and located near the inner surface of the . shielding structure facing the plasma in the confined region. The outer radius of the confined region is $6 \mathrm{~m}$ and the confined volume is $652 \mathrm{~m}^{3}$.

The distance from the outer edge of the plasma to the first conducting wall is $1 \mathrm{~m}$ in the case of flibe $(0.5 \mathrm{~m}$ from the plasma edge to the low conductivity flibe and $0.5 \mathrm{~m}$ of flibe to the $30 \mathrm{~mm}$ thick stainless steel wall). In the case of SnLi the conducting liquid wall is $0.5 \mathrm{~m}$ away from the plasma. 


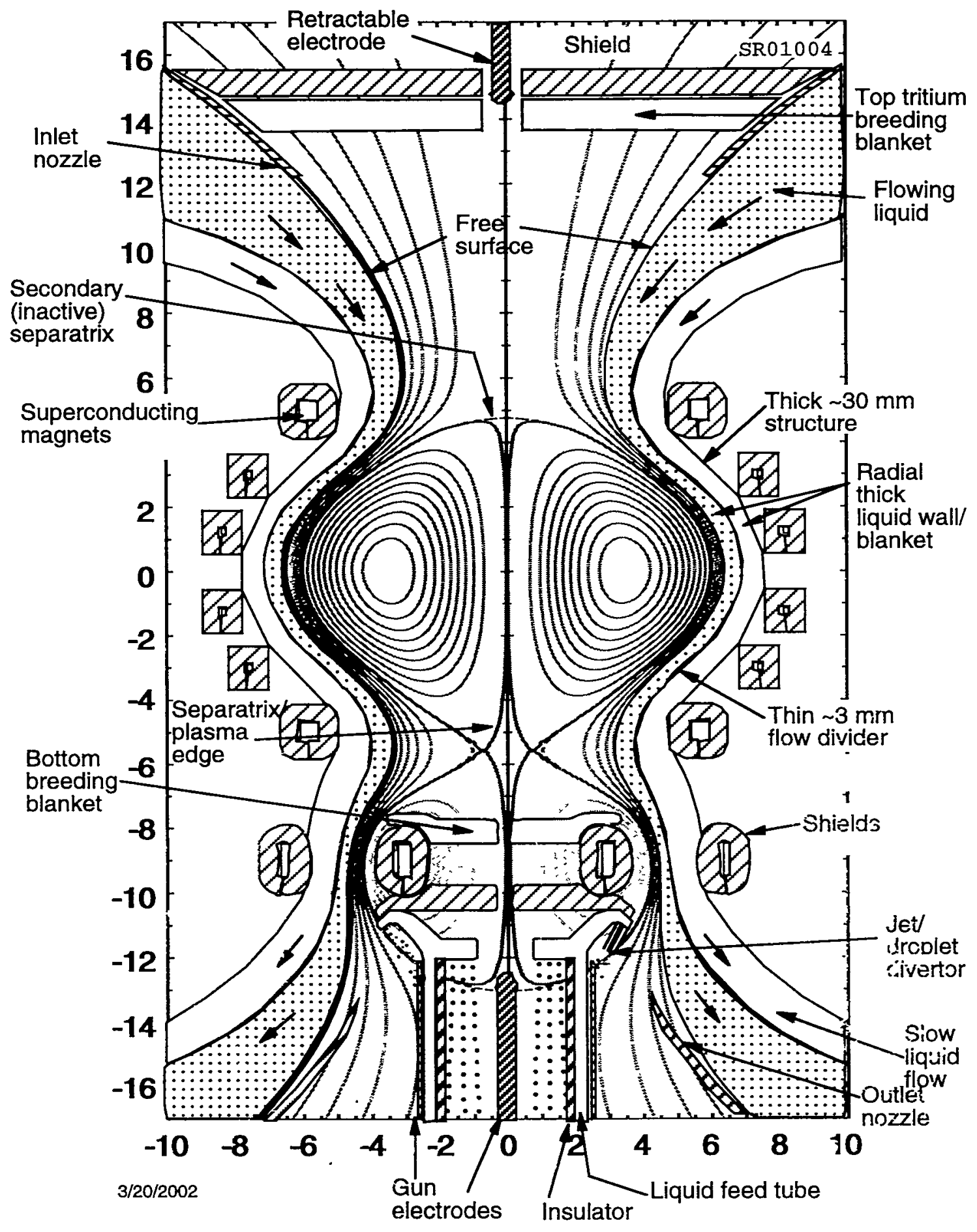

Fig. 1. The spheromak configuration with liquid walls shown above is the subject of this report. The liquid flow is kept to the outside by centrifugal force for molten salt and by magnetic guide field for liquid metals. Liquid jets greatly aid divertor heat removal. 
The current profile deviates from the relaxed Taylor-state in that the $\lambda$-profile (normalized current density, see [1]):

$$
\lambda(\psi)=\frac{\mu_{0} \mathbf{j} \cdot \mathbf{B}}{B^{2}}
$$

varies as shown in Fig. 2, creating shear consistent with a Mercier beta limit of $10 \%$. The value of $\lambda$ on the open field-lines is about half that at the magnetic axis. The pressure profile, as shown also shown in Fig.2, has been optimized to yield the maximum Mercier limit for the given $\lambda$-profile. The $q$-profile varies from 0.9 on the magnetic axis to 0.3 near the edge.

The toroidal current is $40 \mathrm{MA}$ which results in $\mathrm{B}_{\varphi} \approx \mathrm{B}_{\theta}=2.89 \mathrm{~T}$ at the magnetic axis $^{1}$ (magnetic field profiles are shown in Fig. 3). This level of current requires pack current densities of $\sim 30 \mathrm{~A} / \mathrm{mm}^{2}$ in the shaping coils (near a practical limit) with the sizes as shown in Fig. 1. As noted, the toroidal current will have to increase as the design evolves, with the coil currents increasing in direct proportion. Therefore, the coil cross-sectional dimensions will have to increase by about $25 \%$ to keep the current densities within limits.

The main equilibrium parameters are summarized in Table 1 . Note the gun current in the equilibrium model, $18.2 \mathrm{kA}$, is significantly less than the $100 \mathrm{kA}$ value discussed in the gun model section later on. This discrepancy is due to the particular values of the toroidal current and the ratio of $\lambda_{\text {ext }} / \lambda_{0}$ used in the equilibrium model, and needs to be resolved as the design evolves.

Another area for future work involves the edge-flux expansion ratio from the midplane to the divertor region. In the present design, the radial distance between the edge of the confined region and the inactive separatrix ( $\Psi=0$ 
contour) is $1.5 \mathrm{~mm}$ and only expands by a factor of 4 to $6 \mathrm{~mm}$ in the divertor region. This expansion ratio needs to increase by a factor of 2 to $12 \mathrm{~mm}$ in the divertor region to be able to handle the power flux density discussed in the divertor section. This change will require an adjustment in the current and in the position of the outer divertor coil. Perhaps it will also require an additional divertor coil.

Table 1

Equilibrium parameters

\begin{tabular}{|l|c|}
\hline Toroidal current, MA & 40 \\
\hline Toroidal B-field (axis), T & 2.89 \\
\hline Poloidal current (gun), $\mathrm{kA}$ & 18.2 \\
\hline Poloidal B-field ( $\mathrm{R}=0$ ), $\mathrm{T}$ & 5.24 \\
\hline $\begin{array}{c}\text { Poloidal flux (edge), } \mathrm{Wb} \\
\text { (r=0 to separatrix) }\end{array}$ & 0.08 \\
\hline Poloidal flux (axis), $\mathrm{Wb}$ & 75.8 \\
\hline Separatrix radius, inner, $\mathrm{m}$ & 0.068 \\
\hline Separatrix radius, outer, $\mathrm{m}$ & 6.00 \\
\hline Magnetic axis radius, $\mathrm{m}$ & 3.49 \\
\hline Core plasma volume, $\mathrm{m}^{3}$ & 652 \\
\hline Core plasma surface, $\mathrm{m}^{2}$ & 362 \\
\hline Volume average beta, $\%$ & 10 \\
\hline
\end{tabular}

\footnotetext{
' This field level is not yet consistent with the total fusion power. The toroidal current will have to be increased to $\sim 60 \mathrm{MA}$ to produce the desired $4.3 \mathrm{~T}$ field level if this is the correct field to scale from (see the next section for a discussion of scaling and further work needed).
} 


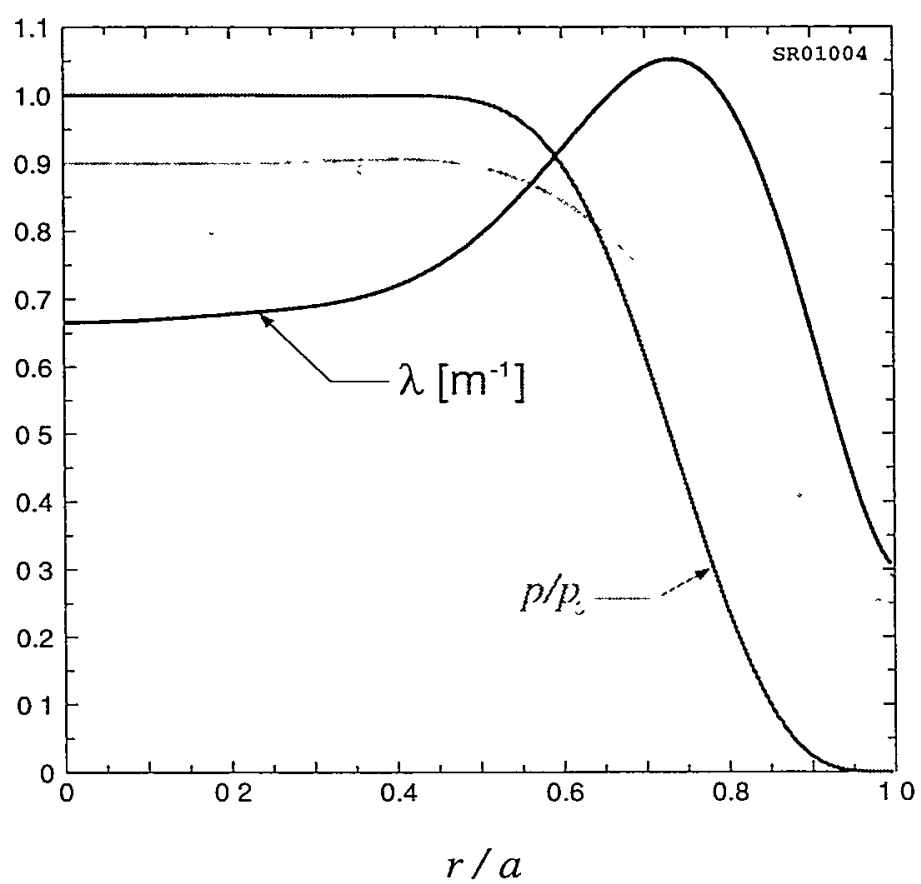

Fig. 2. Profiles of pressure, current $(\lambda)$ and Safety Factor (q) at the midplane.

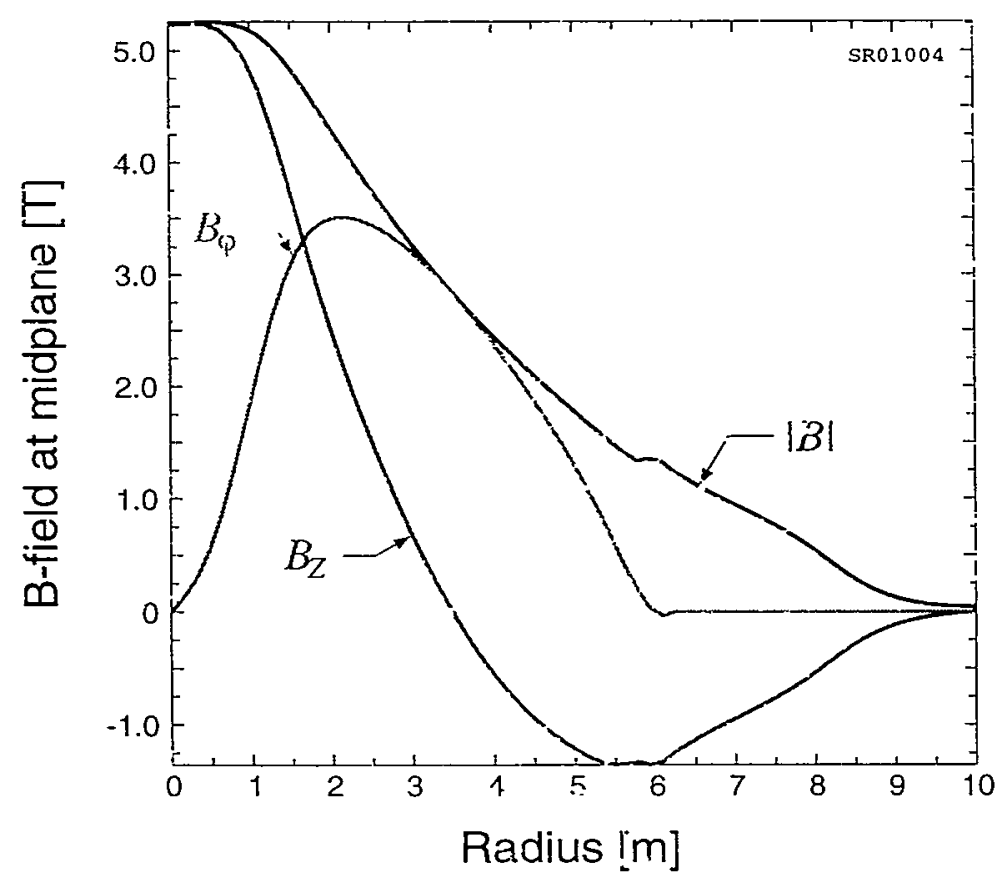

Fig. 3. Magnetic field profile. The field is consistent with a model having 40 MA toroidal current and beta equal to $10 \%$ volume averaged 


\section{Plasma parameters}

The Corsica model has a plasma pressure such that the volume averaged beta is $10 \%$. The field of $5.24 \mathrm{~T}$ on $\mathrm{r}=0$ axis, which corresponds to a $40 \mathrm{MA}$ toroidal current. Based on prior work on the Field Reversed Configuration (FRC) [7], we can scale to get a first approximation of some of the parameters. First we scale the power density.

$$
\begin{aligned}
& \frac{P_{F R C}}{V}=\frac{2500}{2.6}=961.5 \frac{\mathrm{MW}}{\mathrm{m}^{3}} \quad \mathrm{r}=0.39 \mathrm{~m} \text { separatrix case for FRC for scaling } \\
& \frac{P_{\text {Spheromak }}}{V}=\frac{2500}{652}=3.834 \frac{\mathrm{MW}}{\mathrm{m}^{3}} \\
& \frac{P}{V} \propto n^{2} \propto \frac{\beta^{2} B^{4}}{T^{2}} \\
& \frac{\left(\beta^{2} B^{4}\right)_{S p h}}{\left(\beta^{2} S^{4}\right)_{F R C}}=\frac{3.834}{961.5}=3.988 \cdot 10^{-3}
\end{aligned}
$$

From Table 2 we see the FRC field is $5.5 \mathrm{~T}$ but this is on the $\mathrm{x}=0$ axis (the field on . the magnetic axis is zero for the FRC).

$$
B_{S, i i}=\left(3.988 \cdot 10^{-3} \cdot 0.97^{2} \cdot 5.5^{4} / 0.1^{2}\right)^{\frac{1}{4}}=4.305 T
$$

This value of magnetic field probably corresponds to the value somewhere beiween the $\mathrm{r}=0$ axis of $2.89 \mathrm{~T}$ and that at the magnetic axis of $5.24 \mathrm{~T}-\mathrm{a}$ reisonable first guess. A better estimate is left to future work.

The plasma density is also scaled from the FRC work.

$$
n_{s p l,} \propto \frac{1}{\sqrt{\frac{P}{V}}}
$$


$n_{S p h}=26 \cdot 10^{20} \sqrt{\frac{3.834}{961.5}}=1.64 \cdot 10^{20} / \mathrm{m}^{3}$

The volume within the last closed flux contour is $652 \mathrm{~m}^{3}$. The circumference in the poloidal plane of the last flux contour is $24.3 \mathrm{~m}$. The area within this contour in the poloidal plane is $37.9 \mathrm{~m}^{2}$. The surface area from the separatrix to the upper apex along the inside or nearest the axis is about $23 \mathrm{~m}^{2}$ and the area on the outside is $362 \mathrm{~m}^{2}$. This may be useful in deciding how much leakage plasma should enter the divertor on the outside versus the inside. Using the area ratio suggests the inside plasma leakage is only $6 \%$ of the outside leakage. We need to estimate the width of plasma flow on the inside flux surface to estimate the power density there. If we can show the power density on the inside divertor is small. We need only treat the outside divertor (see section on divertor). 
Table 2

Typical spheromak power plant parameters.

\begin{tabular}{|c|c|c|c|}
\hline & Spheromak & FRC & FRC \\
\hline Liquid wall radius, $m$ & 6.5 & 1.5 & 2.0 \\
\hline Separatrix radius, $m$ & $0.068,6.0$ & 0.39 & 1 \\
\hline Magnetic axis, $\mathrm{m}$ & 3.49 & 0.29 & 0.75 \\
\hline $\begin{array}{l}\text { Separatrix length, outside } \\
\text { and inside, } m\end{array}$ & 15,10 & 8 & 8 \\
\hline $\begin{array}{l}\text { Liquid flow path length, inlet } \\
\text { nozzle exit nozzle, } m\end{array}$ & 27 & 14 & 14 \\
\hline Core plasma volume, $\mathrm{m}^{3}$ & 652 & 2.6 & 25 \\
\hline Outer plasma area, $\mathrm{m}^{2}$ & 362 & 75 & 100 \\
\hline $\begin{array}{l}\text { Average ion temperature, } \\
\mathrm{keV}\end{array}$ & 12 & 12 & 18 \\
\hline Average ion density, $10^{20} \mathrm{~m}^{-3}$ & 1.65 & 26 & 6.2 \\
\hline Peak ion density, $10^{20} \mathrm{~m}^{-3}$ & $?$ & 31 & 6.8 \\
\hline$Z_{\text {eff }}$ & 1.5 & 1.5 & 1.5 \\
\hline $\begin{array}{l}\mathrm{s}=\text { plasma radius } / \\
\text { average larmor radius }\end{array}$ & 1100 & 7.5 & 26 \\
\hline $\begin{array}{l}\text { Helicity current drive, } \mathrm{kA} \\
\text { Telicity (Gun) power, } \mathrm{MW}\end{array}$ & $\begin{array}{l}100 \\
125\end{array}$ & $\cdots$ & -- \\
\hline Toroidal current, MA & 40 & & 40 \\
\hline Volume-averaged beta & 0.1 & 0.97 & 0.78 \\
\hline $\begin{array}{ll}\text { Magnetic field, } \mathrm{T} & \text { Poloidal } \\
& \text { Toroidal }\end{array}$ & $\begin{array}{l}\mathrm{Bz}=5.24 @ \mathrm{r}=0 \\
\mathrm{~B} \phi=2.89 @ \mathrm{r}=3.49\end{array}$ & 5.5 & 3.6 \\
\hline $\begin{array}{c}\text { Flux from } r=0 \text { to the } \\
\text { separatrix, } \mathrm{Wb}\end{array}$ & 0.08 & $-\cdots$ & -- \\
\hline $\begin{array}{l}\text { Flux from separatrix to mag } \\
\text { axis, } \mathrm{Wb}\end{array}$ & 75.8 & -- & -- \\
\hline Energy confinement time, $s$ & ? & 0.08 & 0.33 \\
\hline
\end{tabular}




\begin{tabular}{|l|l|l|l|}
\hline Ash particle conf. time, s & $?$ & 0.16 & 0.65 \\
\hline $\begin{array}{l}\text { Neutron wall load ave, } \\
\mathrm{MW} / \mathrm{m}^{2}\end{array}$ & 5.5 & 27 & 18 \\
\hline Surface heat load, MW $/ \mathrm{m}^{2}$ & 0.47 & 1.7 & 1.2 \\
\hline Neutron power, MW & 2000 & 2000 & 1844 \\
\hline $\begin{array}{l}\text { Bremsstrahlung radiation } \\
\text { power, MW }\end{array}$ & $\begin{array}{l}46 \mathrm{MW}, 0.13 \\
\mathrm{MW} / \mathrm{m}^{2}\end{array}$ & 46 & 49 \\
\hline $\begin{array}{l}\text { Line radiation, core @15\% } \\
\mathrm{P}_{\text {alpha, }} \mathrm{MW}\end{array}$ & $\begin{array}{l}75 \mathrm{MW}, 0.21 \\
\mathrm{MW} / \mathrm{m}^{2}\end{array}$ & -- & - \\
\hline $\begin{array}{l}\text { Line radiation, edge@ 10\% } \\
\mathrm{P}_{\text {alpha, }} \mathrm{MW}\end{array}$ & $\begin{array}{l}50 \mathrm{MW}, 0.14 \\
\mathrm{MW} / \mathrm{m}^{2}\end{array}$ & 78 & 69 \\
\hline $\begin{array}{l}\text { Charged-particle transport } \\
\text { power, MW }\end{array}$ & 454 & 415 & 383 \\
\hline Input (Gun) power, MW & $125 @ \mathrm{Q}=20$ & 40 & 40 \\
\hline Fusion power, MW & 2500 & 2500 & 2306 \\
\hline Net electric power, MWe & 1000 & 1000 & 1600 \\
\hline
\end{tabular}

\section{Current Drive Model}

The maguetized Marshall gun used to create andisustain spheromaks can be. represented by an electric ciccuit in which the helicity injection impedance is approximated by a resistor, $R_{s}$, giving a total gun impedance [8]:

$$
\mathrm{R}_{\mathrm{CUN}}=(5 \mathrm{~T} / \mathrm{I})+\mathrm{R}_{\mathrm{FC}}+\cdot \mathrm{R}_{\mathrm{S}}
$$

where $J$ is the gun current; $5 \mathrm{~T}$ is the approximate sheath voltage with . temperature $\mathrm{T}$ (in $\mathrm{eV}$ ) in the "flux core" that guides the gun bias flux and current along the geometric axis of the machine; and $\mathrm{R}_{\mathrm{FC}}$ is the ohmic resistance in the 
flux core. Only $R_{s}$ is useful in sustaining the spheromak, with an efficiency $f$, giving as the requirement for steady state:

$$
\mathrm{fI}^{2} \mathrm{R}_{\mathrm{S}}=\mathrm{P}_{\Omega}=\mathrm{E} / \tau=14 \mathrm{MW}
$$

where $P_{\Omega}$ is the ohmic dissipation of the spheromak with magnetic energy $E$ and decay time $\tau$ that we estimate as $E=700 \mathrm{MJ}$ and $\tau=50 \mathrm{~s}$ for the parameters in Table 2. Finally, an optimum efficiency of $f=0.5$ is obtained for a gun current given by $[7,8]$ :

$$
\mathrm{I}=\mathrm{f}^{-1}\left(5 / \mathrm{R} \mu_{\mathrm{o}}\right) \Psi=100 \mathrm{kA}
$$

where $5 / R$ is the lowest Taylor eigenvalue for flux conserver radius $R=6 \mathrm{~m}$ for the design shown here and flux core $\psi=0.08 \mathrm{~W}$ (the flux between $\mathrm{r}=0$ and the separatrix). Scaling from SSPX gives $\mathrm{T}=50 \mathrm{eV}$ and $\mathrm{R}_{\mathrm{FC}}=1.4 \mathrm{~m} \Omega$ if we take an effective length $\approx R$ along the goemetric axis in the the confinement region where the magnetic field $\mathrm{B}$ is highest and the cross-sectional area of the flux core (= $\psi / B$ ) is smallest [8].

The above formulas give the gun parameters in Table 4 , which in turn give those of Table 2.

Table 4.

Gun Parameters

\begin{tabular}{|l|l|}
\hline Gun Current, I (kA) & 100 \\
\hline Helicity injection impedance, $R_{\mathrm{S}}(\mathrm{m} \Omega)$ & 2.8 \\
\hline Total gun impedance, $\mathrm{R}_{\mathrm{GUN}}(\mathrm{m} \Omega)$ & 6.7 \\
\hline Gun voltage, $\mathrm{I} \mathrm{R}_{\mathrm{GUN}}(\mathrm{V})$ & 670 \\
\hline Power consumed by the gun, $\mathrm{I}^{2} \mathrm{R}_{\mathrm{GUN}}(\mathrm{MW})$ & 67 \\
\hline Gun power supply power, $\mathrm{P}(\mathrm{MW})$ & 125 \\
\hline
\end{tabular}

To limit the gun power to $125 \mathrm{MW}$, giving the nominal fusion gain $Q=20$ in Table 2, requires a total impedance $\mathrm{P} / \mathrm{I}=12.5 \mathrm{~m} \Omega$, calling for a not-unreasonable 
d.c. power supply impedance $12.5-6.7=5.8 \mathrm{~m} \Omega$ and an overall efficiency to sustain the spheromak $=\mathrm{P}_{\Omega} / \mathrm{P}=14 / 125=11 \%$.

The unknown physics resides in the helicity injection impedance $R_{S}$-the subject of ongoing research in SSPX. The required value $R_{S}=2.8 \mathrm{~m} \Omega$ in Table 4 is consistent with an enhanced resistance model of SSPX results, giving [8]:

$$
R_{\mathrm{S}}=f\left(1-f^{2}\right)(\alpha \beta) R_{\mathrm{FC}} \quad=\quad 2.5 \mathrm{~m} \Omega
$$

with $\mathrm{f}=0.5$ as above and $\alpha \beta=4.8$ to fix SSPX data [7]. The actual impedance may be higher, giving somewhat different bias flux and current, greater efficiency, and higher $Q$ (e.g. $R_{S} \approx 10 \mathrm{~m} \Omega$ in earlier CTX results at Los Alamos [9]). The larger question is whether the instability processes of magnetic tearing and reconnection-thought to underlie the helicity injection impedance characteristic of short pulse experiments to date (milliseconds)-will persist in steady state.

\section{Electrode design}

The electrodes shown at the bottom of Fig. 1 provides the $100 \mathrm{kA}$ of helicity current drive. Its active area is a disk of about $0.25 \mathrm{~m}$ radius. This gives a current density of $50 \mathrm{~A} / \mathrm{cm}^{2}$. A tapered electrode could reduce this current density and might ease cooling

\section{Insulator design}

The insulator is a cylindrical sleeve of radius $2 \mathrm{~m}$ about $5 \mathrm{~m}$ long, shown near the bottom of Fig. 1. Its purpose is to prevent current from passing across the gap between the center electrode at $r=0.25 \mathrm{~m}$ and the cylindrical electrode at $\mathrm{r} \approx 2.2$ $\mathrm{m}$. The insulator is shielded from line-of-sight radiation. The neutrons and $\mathrm{x}$-rays dose rate to the insulator from indirect radiation needs to be calculated to determine its lifetime. 


\section{Power plant considerations}

In this section we discuss the power flows. We assume $2500 \mathrm{MW}$ of fusion power. Of this, $2000 \mathrm{MW}$ is in the form of $14 \mathrm{MeV}$ neutrons. Nuclear reactions in the flinabe blanket are assumed to multiply this by 1.18 , giving $2360 \mathrm{MW}$ thermal power in the blanket. To this we add the incident power of the $500 \mathrm{MW}$ from alpha energy which all gets into the flowing fluid either in the walls or in the divertor. Also we add the helicity injection power. We assume a $Q=P_{\text {fusion }} / P_{\text {injection }}=20$ case, so $P_{\text {injection }}=125 \mathrm{MW}$. The total power going into the flowing fluid is $2985 \mathrm{MW}$.

2360 MW nuclear power in the blanket

$500 \mathrm{MW}$ alpha power

$125 \mathrm{MW}$ injection power

2985 MW total

The volumetric flow rate $(\dot{V})$ is given by the flow at $10 \mathrm{~m} / \mathrm{s}$ at the midplane with a $0.5 \mathrm{~m}$ thickness. The flow in the divertor jets and the slow flow in the back of the blanket are small compared to this.

$\ddot{V}=A V=2 \pi r \Delta r v=2 \pi 6.5 \cdot 0.5 \cdot 10=204.2 \mathrm{~m}^{3} / \mathrm{s}$

For flibe:

The mass flow rate (see Fig. 5) is:

$\dot{m}_{\text {blanket }}=2000 \mathrm{~kg} / \mathrm{m}^{3} \cdot 204.2 \mathrm{~m}^{3} / \mathrm{s}=4.084 \cdot 10^{5} \mathrm{~kg} / \mathrm{s}=$ flow through blanket

The temperature increase in the mixed flow from inlet to outlet is:

$\Delta T_{\text {blanket }}=\frac{P}{C \dot{m}_{\text {blanket }}}=\frac{2985 \mathrm{MW}}{2380 \mathrm{Jkg}^{-1} \mathrm{~K}^{-1} \cdot 4.084 \cdot 10^{5} \mathrm{~kg} / \mathrm{s}}=3.071 \mathrm{~K}$

Past studies suggest a $100^{\circ} \mathrm{C}$ temperature drop in the coolant to and from the heat exchangers is acceptable from an economic standpoint. We desire lower temperatures and use only $50^{\circ} \mathrm{C}$ to keep the surface temperature low. This assumption will result in a modest plant cost increase. 
$\dot{m}_{H X}=\frac{P}{C \Delta T}=\frac{2985 M W}{2380 \mathrm{Jg}^{-1} \mathrm{~K}^{-1} 50 \mathrm{~K}}=2.5084 \cdot 10^{4} \mathrm{~kg} / \mathrm{s}=$ flow to heat exchanger

Since the blanket flow rate is larger than the flow to the heat exchanger, a fraction of the flow will be bypassed to the heat exchanger.

$\dot{m}_{b \text { ppass }}=\dot{m}_{\text {blanker }}-\dot{m}_{H X}=4.084 \cdot 10^{5} \mathrm{~kg} / \mathrm{s}-2.5084 \cdot 10^{4} \mathrm{~kg} / \mathrm{s}=3.833 \cdot 10^{5} \mathrm{~kg} / \mathrm{s}$

The temperature of the flow to the heat exchanger is assumed to be $450^{\circ} \mathrm{C}$ and $400{ }^{\circ} \mathrm{C}$ of the flow out. The melt temperature is estimated at $350^{\circ} \mathrm{C}$ (perhaps as low as $\left.310^{\circ}\right)$ for flinabe, giving a small margin $\left(50^{\circ} \mathrm{C}\right)$. Flibe has a melt temperature of $460^{\circ} \mathrm{C}$.

\section{For SnLi:}

The nass flow rate (see Fig. 5) is:

$\dot{m}_{\text {blanket }}=6000 \mathrm{~kg} / \mathrm{m}^{3} \cdot 204.2 \mathrm{~m}^{3} / \mathrm{s}=12.25 \cdot 10^{5} \mathrm{~kg} / \mathrm{s}=$ flow through blanket

The temperature increase in the mixed flow from inlet to outlet is:

$$
\begin{aligned}
& \Delta T_{\text {blanket }}=\frac{P}{C \dot{m}_{\text {blanket }}}=\frac{2985 \mathrm{MW}}{318.1 \mathrm{Jkg}^{-1} \mathrm{~K}^{-1} \cdot 12.25 \cdot 10^{5} \mathrm{~kg} / \mathrm{s}}=7.659 \mathrm{~K} \\
& \dot{m}_{H X}=\frac{P}{C \Delta T}=\frac{2985 \mathrm{MW}}{318.1 \mathrm{Jg}^{-1} \mathrm{~K}^{-1}} \frac{}{100 \mathrm{~K}}=0.9384 \cdot 10^{5} \mathrm{~kg} / \mathrm{s}
\end{aligned}
$$

Since the blanket flow rate is larger than the Ilow rate to the heat exchanger, a fraction of the flow will be bypassed to the heat exchanger.

$$
\dot{m}_{b y p a s s}=\dot{m}_{\text {blanket }}-\dot{m}_{H X}=12.25 \cdot 10^{5} \mathrm{~kg} / \mathrm{s}-0.9384 \cdot 10^{5} \mathrm{~kg} / \mathrm{s}=11.31 \cdot 10^{5} \mathrm{~kg} / \mathrm{s}
$$

For Li:

The mass flow rate (see Fig. 5) is:

$\dot{m}_{\text {blanket }}=485 \mathrm{~kg} / \mathrm{m}^{3} \cdot 204.2 \mathrm{~m}^{3} / \mathrm{s}=0.9904 \cdot 10^{5} \mathrm{~kg} / \mathrm{s}=$ flow through blanket

The temperature increase in the mixed flow from inlet to outlet is:

$$
\begin{aligned}
& \Delta T_{\text {hlanket }}=\frac{P}{C}=\frac{2985 \mathrm{MW}}{4200 \mathrm{Jkg}^{-1} \mathrm{~K}^{-1} \cdot 0.9904 \cdot 10^{5} \mathrm{~kg} / \mathrm{s}}=7.176 \mathrm{~K} \\
& \dot{m}_{H X}=\frac{P}{C \Delta T}=\frac{2985 \mathrm{MW}}{4200 \mathrm{Jg}^{-1} \mathrm{~K}^{-1} 50 \mathrm{~K}}=1.421 \cdot 10^{4} \mathrm{~kg} / \mathrm{s}
\end{aligned}
$$


Since the blanket flow rate is larger than the flow rate to the heat exchanger, a fraction of the flow will be bypassed to the heat exchanger.

$$
\dot{m}_{\text {bypass }}=\dot{m}_{\text {blanket }}-\dot{m}_{H X}=0.99037 \cdot 10^{5} \mathrm{~kg} / \mathrm{s}-1.421 \cdot 10^{4} \mathrm{~kg} / \mathrm{s}=8.482 \cdot 10^{4} \mathrm{~kg} / \mathrm{s}
$$

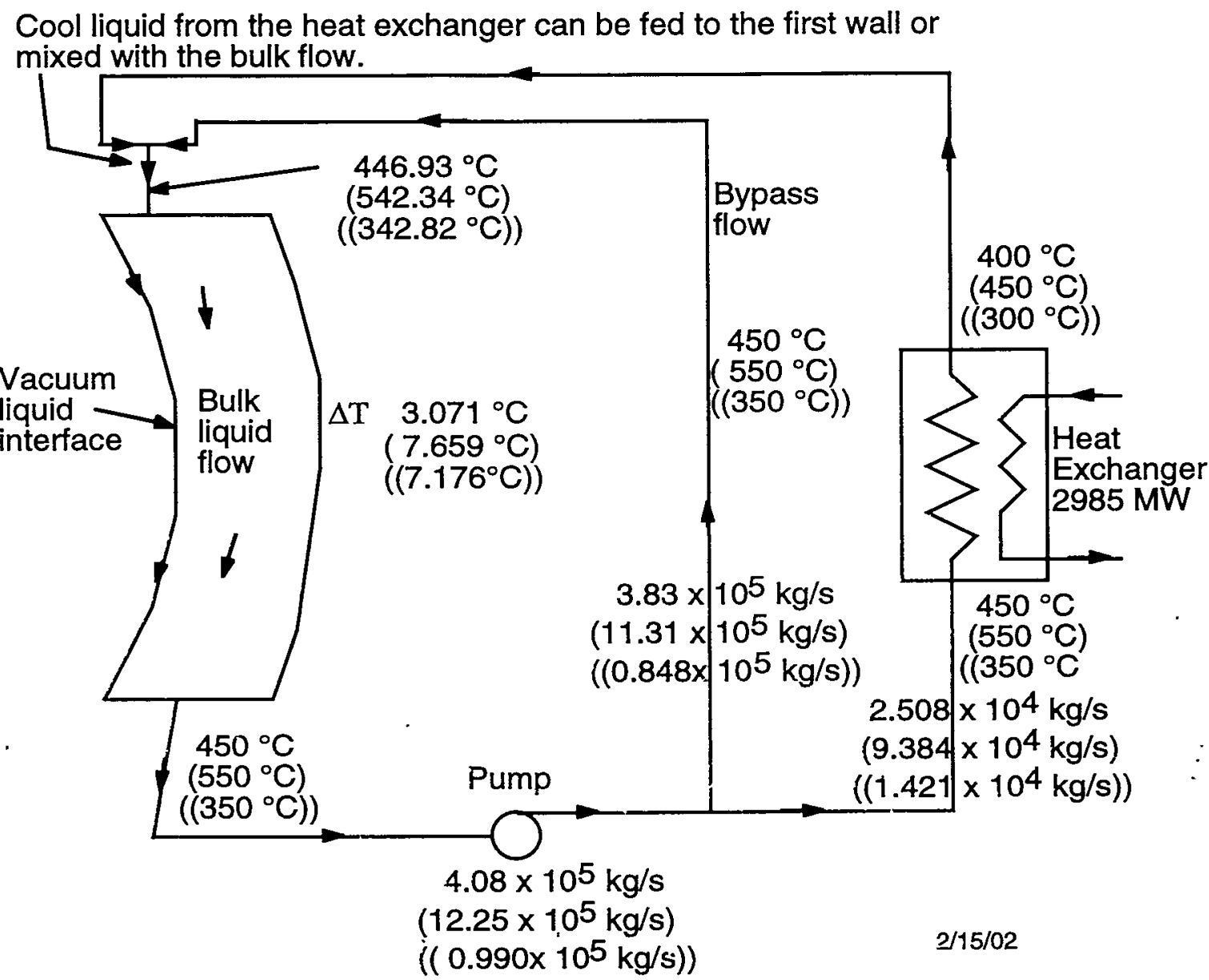

Fig 4. Mass flow and temperature diagram for flibe as the liquid wall.

Numbers in parentheses are for SnLi and double parentheses are for Li.

Issues for flibe/flinabe case:

$1-\Delta \mathrm{T}=50^{\circ} \mathrm{C}$ across heat exchanger is low. There will be an economic penalty for having so low a value $\left(100^{\circ} \mathrm{C}\right.$ is customary).

$2-\mathrm{T}_{\text {cold }}=400^{\circ} \mathrm{C}$ is close to the melt temperature, assumed to be $350^{\circ} \mathrm{C}$. Freeze-up will be an operational issue. Perhaps the melt temperature will be $310^{\circ} \mathrm{C}$ and the temperature can be lowered somewhat. 
3- $\mathrm{T}_{\text {hot }}=450^{\circ} \mathrm{C}$ is low for Carnot efficiency, so there will be an economic penalty ( $650^{\circ} \mathrm{C}$ is customary).

Issues for SnLi case:

These seem reasonable from power plant point of view.

Issues for Li case:

$1-\Delta \mathrm{T}=50^{\circ} \mathrm{C}$ across heat exchanger is low. There will be an economic penalty for having so low a value $100^{\circ} \mathrm{C}$ is usual).

2- $\mathrm{T}_{\text {hot }}=350^{\circ} \mathrm{C}$ is low for Carnot efficiency, so there will be an economic penalty (550 ${ }^{\circ} \mathrm{C}$ is customary for a liquid metal system).

\section{Liquid wall design}

The liquid flows in from the top in Fig. 1 with a nominal speed fo $10 \mathrm{~m} / \mathrm{s}$. In the case of flinabe there is enough azimuthal speed to keep the liquid on the outer wall by centrifugal force as shown by K. Gulec in related prior studies [Ref. 7, p 5-94 to 5-105]. In the case of SnLi and Li, we assume the magnetic field will keep the flow closely following field lines. Stability of liquid metal flow is an area needing study.

'The 1 of the liquid is heated up mostly by neutrons by only $3^{\circ} \mathrm{C}$ for flinabe, $7.7^{\circ} \mathrm{C}$ ior $\mathrm{SnLi}$ and $7.2^{\circ} \mathrm{C}$ for Li cases, as shown in Fig. 4 . The radiation in the form of optical line radiation coming from the core inierior and the edge plasma and semsstrahlung radiation from the core heats the liquid near the surface. We neec. th lnow the surface temperature in order to calculate the evaporation rate.

We wil! treat two cases; one with relatively little optical radiation and one-with enharcsid optical radiation. The power flow to the divertor is highest with. the iowest radiation to the wall case. We believe these two extreme cases will bracket the trade-off between a large wall evaporation and large divertor evaporation. 


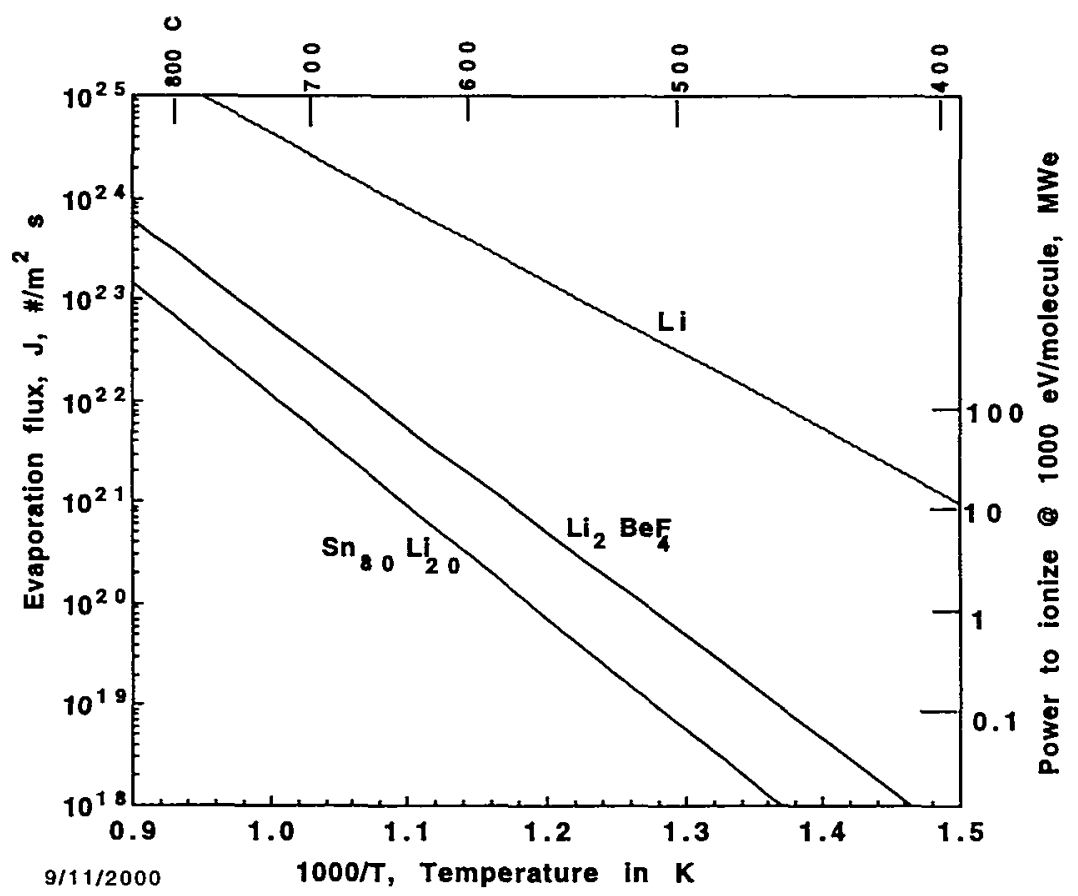

Fig. 5. Evaporation rates into vacuum for candidate liquids based on Ref. 7 p 8-14 to 8-18. The values given are based on data at high temperatures $\sim 1000{ }^{\circ} \mathrm{C}$ and extrapolated to lower temperatures and may be high, especially in the case of flibe.

The vapor pressure for $\mathrm{Li}_{2} \mathrm{BeF}_{4}$ used was $P($ Torr $)=10^{9.00045-10441.05 / T}$ from [10] Cantor, Fisu and Ward (1965). At $500^{\circ} \mathrm{C}$, new theoretical analysis lowers this preciicted value by about a factor of two [11] (Olander, Fukuda, and Baes; Jr;; 2002). Adding $\mathrm{NaF}$ to flibe will lower the vapor pressure further due to dilution of $\mathrm{BeF}_{2}$ and allow operating at a lower temperature for the:inlet liquid due to the lower melt iemperature of flinabe [5] (Peterson, 2001).

From Table 5, we see the low radiation case has $0.35 \mathrm{MW} / \mathrm{m}^{2}$ of optical line radiation surface heat load and $1.29 \mathrm{MW} / \mathrm{m}^{2}$ in the high radiation case. The . Bremsstrahlung radiation for the flibe case was mistakenly left out of the caiculation. Inclusion will raise the film drop by the ratio of $0.45 / 0.35$. For SnLi, the surface heat load is $0.48 \mathrm{MW} / \mathrm{m}^{2}$ and $1.42 \mathrm{MW} / \mathrm{m}^{2}$ for the low and enhanced radiation cases. Photons of $10 \mathrm{keV}$ penetrate $\sim 1 \mathrm{~mm}$ into flibe, whereas the film thickness is about $8 \mathrm{~mm}$ thick. 
Table 5

Liquid wall power flux and temperature parameters

\begin{tabular}{|c|c|c|c|c|}
\hline \multirow{3}{*}{$\begin{array}{l}\text { Type of } \\
\text { power } \\
\text { Brem }\end{array}$} & \multicolumn{2}{|c|}{ Low radiation } & \multicolumn{2}{|c|}{ Enhanced radiation } \\
\hline & \multicolumn{2}{|c|}{$\mathrm{MW} \quad \mathrm{MW} / \mathrm{m}^{2}$} & \multicolumn{2}{|c|}{ MW $\quad \mathrm{MW} / \mathrm{m}^{2}$} \\
\hline & 46 & 0.13 & 46 & 0.13 \\
\hline Line, core & 75 & 0.21 & 280.2 & 0.774 \\
\hline Line, edge & 50 & 0.14 & 186.8 & 0.516 \\
\hline Line, total & 125 & 0.35 & 467 & 1.29 \\
\hline $\begin{array}{l}\text { Charged } \\
\text { power to } \\
\text { divertor }\end{array}$ & 454 & $\begin{array}{l}3720 \\
6 \mathrm{~mm} \text { flux } \\
\text { tube, one- } \\
\text { ended }\end{array}$ & 112 & $\begin{array}{l}918 \\
6 \mathrm{~mm} \text { flux } \\
\text { tube, one- } \\
\text { ended }\end{array}$ \\
\hline$P_{\text {total }}, M W$ & 625 & & 625 & \\
\hline$P_{\text {rad }} / P_{\text {total }}$ & 0.27 & & 0.82 & \\
\hline \multicolumn{5}{|l|}{ Flibe } \\
\hline$\Delta \mathrm{T}_{\text {film }}$ & $27^{\circ} \mathrm{C}$ & & 101 & \\
\hline $\mathrm{T}_{\text {surface }}$ & $479^{\circ} \mathrm{C}$ & & 553 & \\
\hline \multicolumn{5}{|l|}{ SnLi } \\
\hline$\Delta \mathrm{T}_{\mathrm{film}}$ & $83^{\circ} \mathrm{C}$ & & $245^{\circ} \mathrm{C}$ & \\
\hline $\mathrm{T}_{\text {effecitive }}$ & $610^{\circ} \mathrm{C}$ & & $734^{\circ} \mathrm{C}$ & \\
\hline
\end{tabular}

The high Reynolds number (highly turbulent) flowing liquid with a free surface has eddies at the surface causing the surface to undulate. The transverse motion at the surface causes mass transport and therefore enhanced heat transfer over pure conduction. As we move into the liquid, the eddies get larger and heat transfer is enhanced even more by convection. The equivalent thermal conductivity $k_{\text {equivalent }}$ has been calculated by Smolentsev [12], based on models discussed in [13] and plotted in Fig. 6 for flibe divided by the classical thermal conductivity $k$, for the flow speed of $10 \mathrm{~m} / \mathrm{s}$ and $0.5 \mathrm{~m}$ thickness. We take $\mathrm{k}$ to be $1.06 \mathrm{~W} \mathrm{~m}^{-1} \mathrm{~K}^{-1}$. Smolentsev gets an enhancement of thermal conductivity at the free surface of 100 . At the back wall there is a $70 \mu \mathrm{m}$ laminar layer with no transverse motion. Thus the enhancement is unity. We will assume flinabe and flibe have the same properties. 


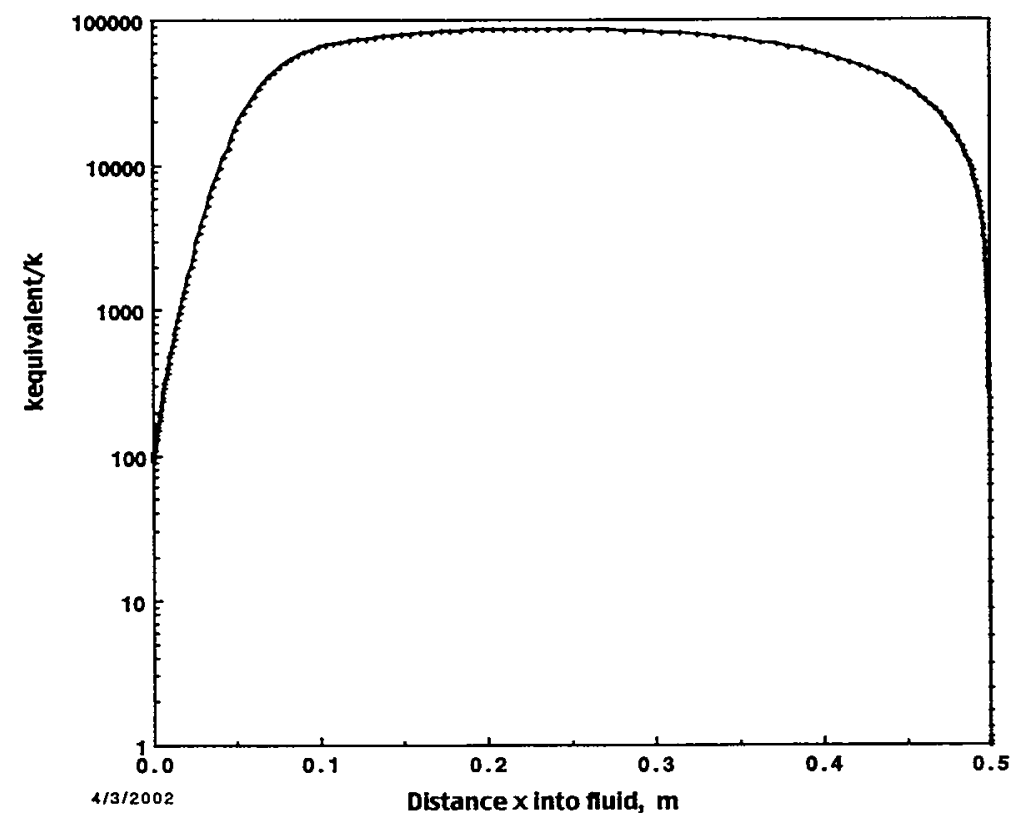

Fig. 6. Thermal conductivity for flinabe and flibe versus distance from the free surface into the flowing liquid.

We can get the temperature profile by integrating the heat conduction equation: $\frac{P}{A}=-k_{\text {equivalent }} \frac{d T}{d x}$

Rearranging terms:

$d T=-\frac{P}{k_{\text {equivalent }} A} d x$

Integrating:

$\Delta T_{\text {film }}=T(x=0)-T(x)=-\int_{0}^{x} \frac{P}{k_{\text {equivaient }} A} d x$

The integral using the variable equivalent thermal conductivity, from Fig. 6 is plotted in Fig. 7. 


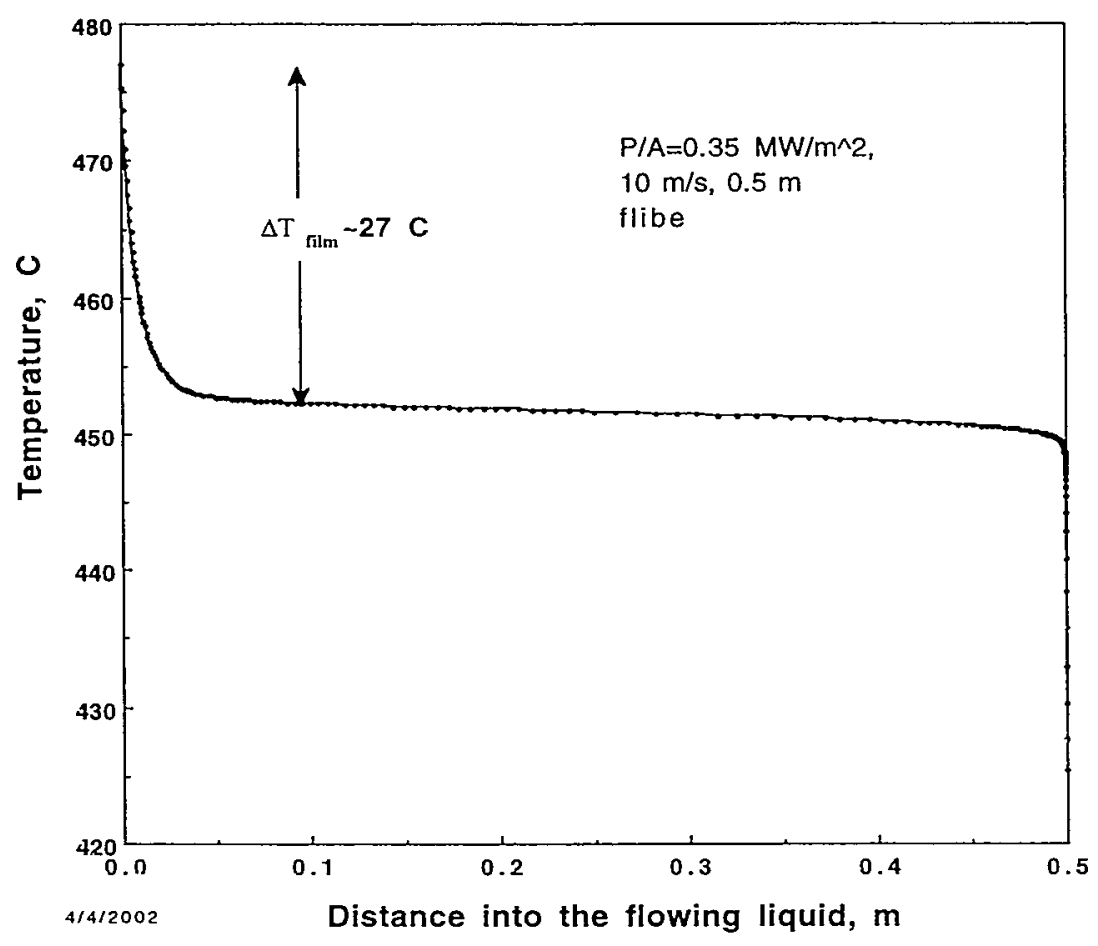

Fig. 7. Temperature profile through the flowing liquid.

There is a film drop on the surface and a flat temperature profile in the very turbulent interior and a film drop on the back wall, which we will ignore because there is very little heat removal there in our case. The heat is practically all . convected out with the flow. 


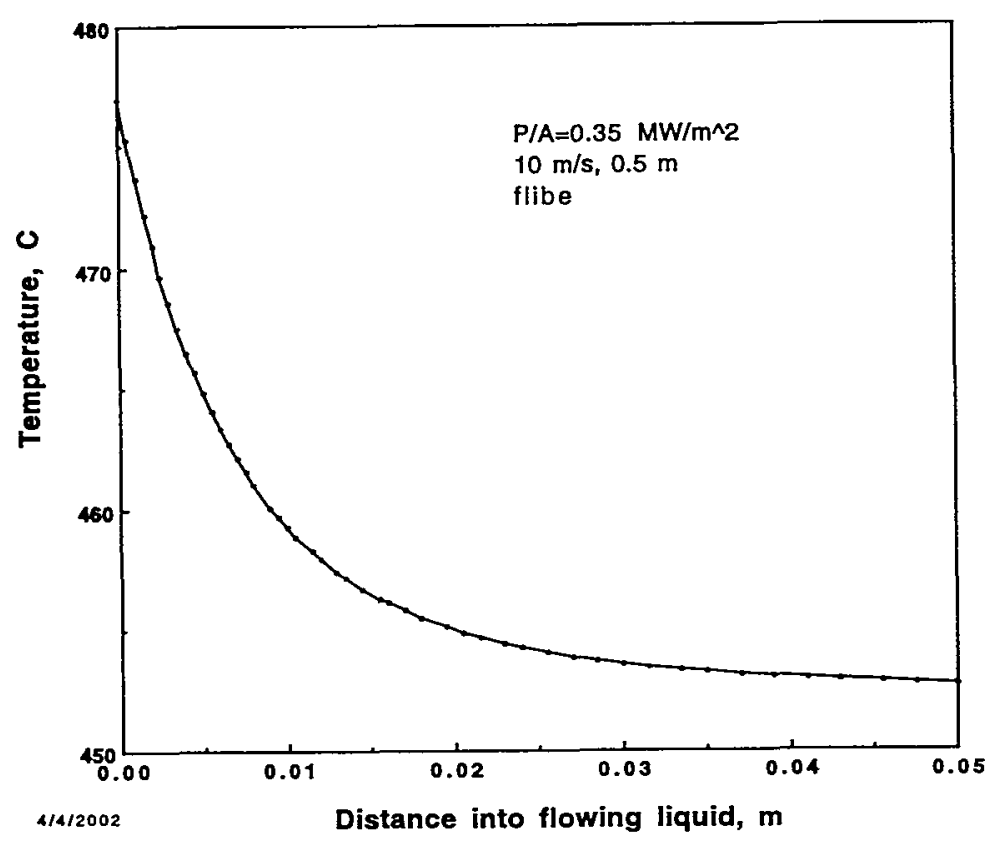

Fig. 8. Temperature profile near the free surface.

The temperature drop from the surface to the interior or bulk is approximately 27 ${ }^{\circ} \mathrm{C}$ for this case, with most of this drop occurring in a distance of $8.5 \mathrm{~mm}$. We call this the surface film. It is seen in Fig. $7 \& 8$ :

It may be useful to use the heat transfer coefficient, $h$, to calculate surface * temperature.

$$
\begin{aligned}
& \frac{P}{A}=h\left(T_{\text {surface }}-T_{\text {bulk }}\right)=h \Delta T_{\text {film }} \\
& h=\frac{k_{\text {equivalent }}(x=0) \frac{d T}{d x}(x=0)}{\Delta T_{\text {fim }}}
\end{aligned}
$$

From Fig. 7 we get the film drop and from Fig. 8 we get the derivative at the surface:

$$
h=\frac{106 \mathrm{~W} / \mathrm{mK} \frac{27 \mathrm{~K}}{0.008 \mathrm{~m}}}{27 \mathrm{~K}}=13,250-\frac{\mathrm{W}}{\mathrm{m}^{2} \mathrm{~K}}
$$

For the liquid metal cases of SnLi and Li, we assume the motion is laminar and use the pure conduction temperature rise formula: 


$$
\Delta T_{\text {film }} \doteq 2 \frac{P}{A} \sqrt{\frac{t}{\pi k \rho C}}
$$

This equation gives the temperature rise as the surface moves along while being heated with a surface heat load of $\mathrm{P} / \mathrm{A}, \mathrm{W} / \mathrm{m}^{2}$. For our case, we take typically 10 $\mathrm{m} / \mathrm{s}$ and $15 \mathrm{~m}$ of path length or $1.5 \mathrm{~s}$ of exposure. The exit temperature equals the entrance temperature $+\Delta \mathrm{T}_{\text {film }}+\Delta \mathrm{T}_{\text {blanket }}$. Typically we have found the average evaporation occurs at a temperature about $3 / 4$ of the way between the inlet and outlet temperature: Let us call this temperature the effective temperature, $T_{\text {eff }}$. $T_{\text {eff }}=T_{\text {trlet }}+\frac{3}{4}\left(\Delta T_{\text {sufface }}+\Delta T_{\text {blanket }}\right)$

For flibe $T_{\text {eff }}=T_{\text {inlet }}+\Delta T_{\text {flim }}+\frac{3}{4} \Delta T_{\text {blanket }}$

Table 6

Summary temperatures for liquid walls

\begin{tabular}{|l|l|l|l|l|l|l|}
\hline & \multicolumn{3}{|l|}{ Low radiation case } & \multicolumn{3}{l|}{ Enhanced radiation case } \\
\hline & Flibe & SnLi & $\mathrm{Li}$ & Flibe & SnLi & $\mathrm{Li}$ \\
\hline$\Delta \mathrm{T}_{\text {film }}{ }^{\circ} \mathrm{C}$ & 27 & 83 & 48 & 101 & 245 & 177 \\
\hline $\begin{array}{l}\mathrm{T}_{\text {eifective }}{ }^{\circ} \mathrm{C} \\
\begin{array}{l}(\mathrm{f} \text {-allowed from } \\
\text { edge plasma } \\
\text { analysis }\end{array}\end{array}$ & 479 & 610 & 384 & 553 & 734 & 481 \\
\hline
\end{tabular}

*The edge plasma will be perturbed for the enhanced radiation case, so that new calculations will be needed.

The average evaporative flux from the wall for flinabe for the low radiation case at $0.35 \mathrm{MW} / \mathrm{m}^{2}$ is $2 \times 10^{19} \mathrm{~m}^{-2} \mathrm{~s}^{-1}$ and at the enhanced racliation case of 1.29 $\mathrm{MW} / \mathrm{m}^{2}$ is $5 \times 10^{20} \mathrm{~m}^{-2} \mathrm{~s}^{-1}$. 
The average evaporative flux from the wall for $\mathrm{SnLi}$ for the low radiation case at $0.48 \mathrm{MW} / \mathrm{m}^{2}$ is $8.9 \times 10^{18} \mathrm{~m}^{-2} \mathrm{~s}^{-1}$ and at the enhanced radiation case of 1.42 $\mathrm{MW} / \mathrm{m}^{2}$ is $8.0 \times 10^{20} \mathrm{~m}^{-2} \mathrm{~s}^{-1}$. The inlet temperature was $542 \mathrm{C}$, and the exit temperatures for the two cases were $626 \mathrm{C}$ and $787 \mathrm{C}$ respectively.

The predicted temperature of the liquid wall due to heating from radiation is lower than the allowed temperature due to contamination from evaporation for the low radiation cases. However, it is higher for the enhanced radiation cases. This result is somewhat encouraging, depending on the amount of optical radiation.

\section{Table 7}

Properties used for candidate liquids

\begin{tabular}{|c|c|c|c|}
\hline $\begin{array}{c}\text { Liquid } \\
\cdot\end{array}$ & $\begin{array}{c}\mathrm{C}, \\
\mathrm{J} / \mathrm{kgK}\end{array}$ & $\begin{array}{c}\mathrm{\rho}, \\
\mathrm{kg} / \mathrm{m} 3\end{array}$ & $\begin{array}{c}\mathrm{k} \\
\mathrm{W} / \mathrm{mK}\end{array}$ \\
\hline Flibe/flinabe & 2380 & 1900 & 1.06 \\
\hline $\mathrm{Li}$ & 4360 & 450 & $53^{*}$ \\
\hline $\mathrm{SnLi}$ & 318 & 6000 & $40^{*}$ \\
\hline $\mathrm{PbLi}$ & 160 & 8700 & $15^{*}$ \\
\hline $\mathrm{Ga}$ & $380^{*}$ & 5900 & $60^{*}$ \\
\hline $\mathrm{Sn}$ & $230^{*}$ & 5700 & $35^{*}$ \\
\hline
\end{tabular}

$* 500 \mathrm{C}^{\circ}$

\section{Divertor design}

The divertor is the region where the leakage plasma disposes of heat and particles and is shown in Fig. 1 (expanded view in Fig. 9). We plan to remove heat by injecting a high speed (up to $100 \mathrm{~m} / \mathrm{s}$ ) set of jets at a small angle to the magnetic flux which guides the plasma flow. The jets are shown in side- and end-views in Fig. 10. The jets can be made to form droplets if desired. 


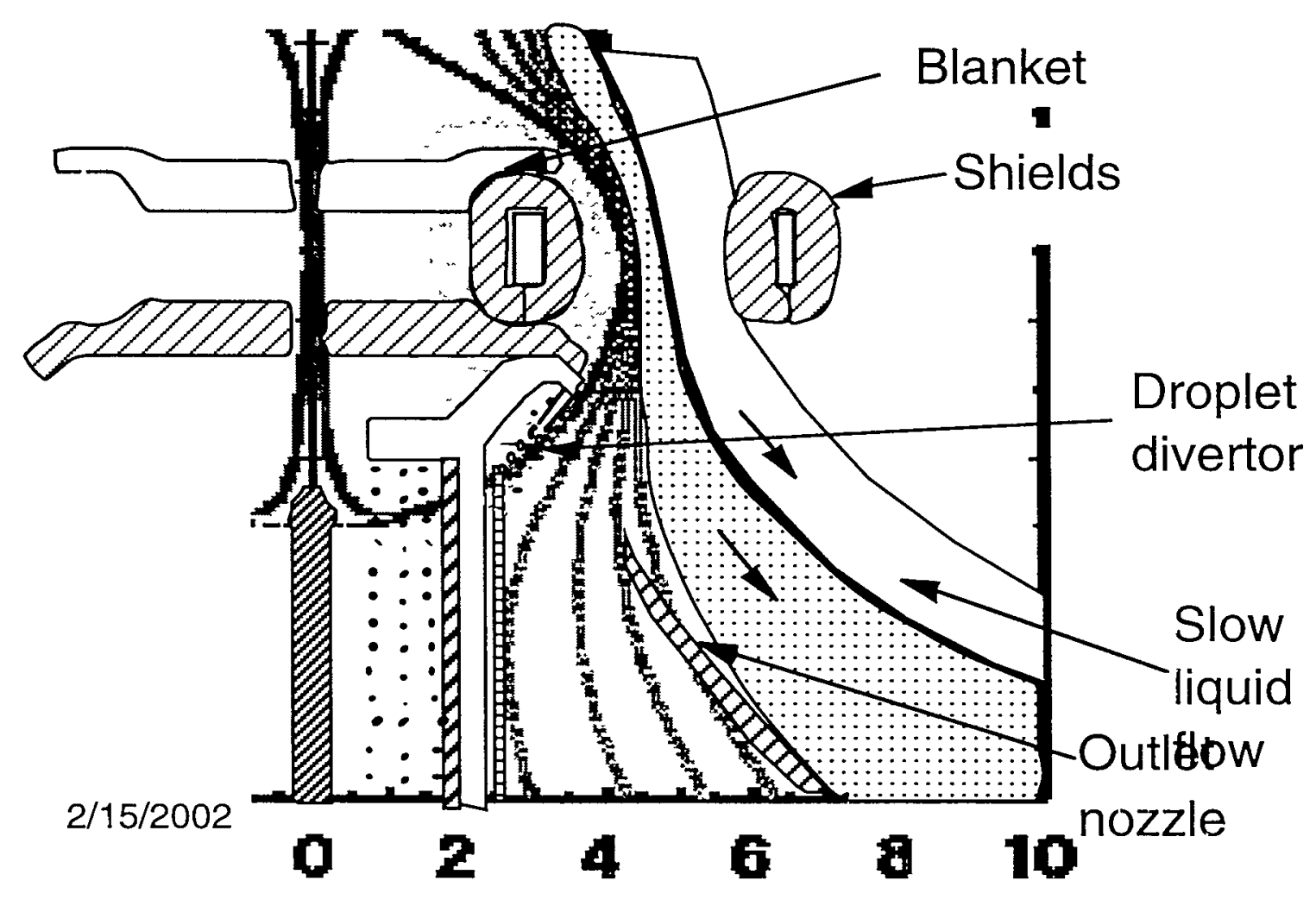

Fig. 9. The jets in the divertor are shown at $5^{\circ}$ to the flux.

A vertical riser tube brings liquid up to an inner and outer spray nozzle. These nozzles spray many rows of small jets or droplets ( $1 \mathrm{~mm}$ dia) to intercept the edge plasma. They carry away heat and provide surface area for condensation of evaporated droplet material. The insulator must be protected from direct particle bombardment either by a sufficiencly dense droplet stream or a low conductivity film on the surface. 


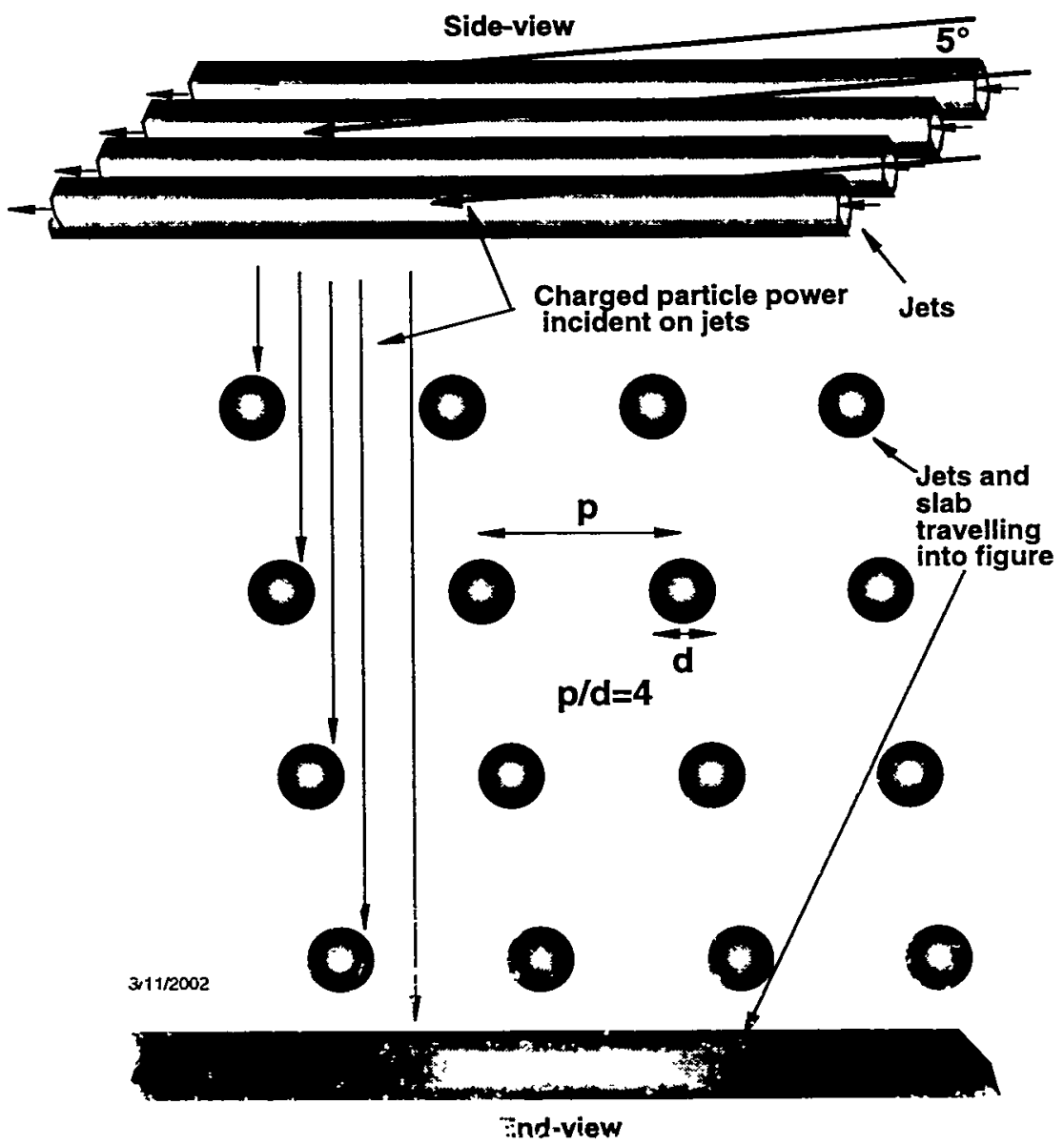

Fig. 10. Side and end-yiew of jets in the divertor are shown ar $5^{\circ}$ the tilix. - .

The distance ar tint midplane of the separatrix $(r=0)$ and the secoms (inactiva).

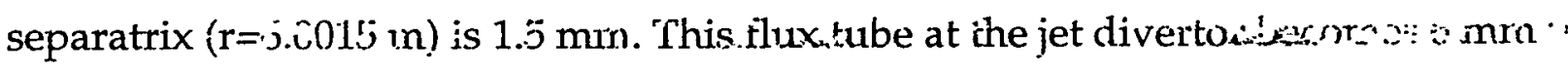
(at $\mathrm{r}=3 \mathrm{~m}, \mathrm{z}=-12$. in). If she leaking plasma that passes across the soy wirix vrere to completely fill this $15 \mathrm{~mm}$ flux tube, all the power would thow io the tive:tor at the bottom. However, the edge plasma, being diffusive, typically ras : dimension an order of magnitude largec than this. Therefore, nearly sgizal amounts would f'ow out the top and through the aperture where the retractable electrode is shorvn in rig. 1. The retractable electrode could be compietely removed during normal operation after start-up. The plasma flowing through this aperture could go into a large tank with plenty of room to spread out the heat. This needs to be looked at in future design studies. 
For the discussion to follow we are going to assume that the $6 \mathrm{~mm}$ wide flow into the bottom divertor takes all of the power and this dimension grows to $12 \mathrm{~mm}$. The enhanced radiation case of $112 \mathrm{MW}$ flowing into the one-ended divertor then produces a power density of $459 \mathrm{MW} / \mathrm{m}^{2}$ over the $12 \mathrm{~mm}$ wide flux tube. If only half of the power flows is out the bottom, then the power density would drop in half to a somewhat more reasonable value of $229 \mathrm{MW} / \mathrm{m}^{2}$ for a double-ended divertor. This change needs to be studied in future iterations of the design.

We now ask what are the evaporation rates for a liquid slab divertor and a jet divertor inclined at a small angle to the flow for a power density of $459 \mathrm{MW} / \mathrm{m}^{2}$. The results for a slab inclined at $5^{\circ}$ with a flow speed of $20 \mathrm{~m} / \mathrm{s}$ are $1.09 \times 10^{28} \mathrm{~m}^{-}$ ${ }^{2} \mathrm{~s}^{-1}$ average flux for flibe and $2.64 \times 10^{22} \mathrm{~m}^{-2} \mathrm{~s}^{-1}$ for $\mathrm{SnLi}$. $\mathrm{T}_{\text {in }}=673 \mathrm{~K}$ and $\mathrm{T}_{\text {out }}=$ $2383 \mathrm{~K}$ for flibe and $\mathrm{T}_{\text {in }}=673 \mathrm{~K}$ and $\mathrm{T}_{\text {out }}=1107 \mathrm{~K}$ for SnLi. $\mathrm{T}_{\text {in }}$ for SnLi should have been $723 \mathrm{~K}$ for consistency with the fluid to the divertor from the cold leg of the hea: exchanger. For four rows of jets $(\mathrm{p} / \mathrm{d}=4)$ followed by a slai as shown in

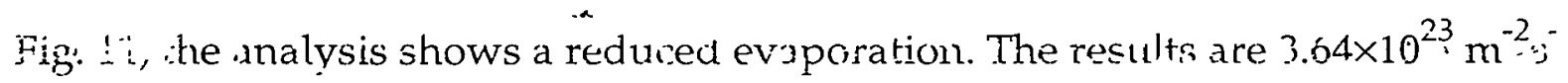
${ }^{3}$ for $:$ ibe and $4.82 \times 10^{18} \mathrm{~m}^{-2} 3^{-4}$ for SnLi. The surprising eduction of ther. evapor. ive flux is due to the rertuction by $A$ factor or 3.14 in average vower. Circulation in the jets, exposing all sides so the incident porser, cesults in a facto: of 3 lowe: temperature rise. This curace a:nparature apoears in the sxponent of the evaporation equation.

For the low radiation case, the charged vower to the divertor of $154 \mathrm{MW}$ over a $12 \mathrm{~mm}$ wide flux tube would resut in $1860 \mathrm{MW} / \mathrm{m}^{2}$. The evaporation with $10 \mathrm{C}$ $\mathrm{m} / \mathrm{s}$ jer speed is estimated at $6.0 \times 10^{25} \mathrm{~m}^{-2} \mathrm{~s}^{-1}$ for flinabe and $1.4 \times 10^{20} \mathrm{~m}^{-2} \mathrm{~s}^{-1}$ for SnLi.

\section{Edge plasma analysis}


The plasma beyond the magnetic separatrix shields the core plasma from the impurities that evaporate from the liquid wall. Here we discuss the modeling of this scrape-off layer (SOL) plasma and present results on the effectiveness of the shielding. With respect to the liquid first-wall, the maximum flux of impurities that the SOL plasma can shield then determines the allowable surface temperature of the liquid. The surface is heated by a combination of bremsstrahlung and line radiation from the core and edge region (see Table 2). The heat flux to the divertor region is also important, because it defines what peak heat flux must be tolerated by the divertor.

The initial model for the edge plasma considers the thin annulus of the edge region as a long-thin plasma slab. The $\mathrm{X}$-points are taken to be $10 \mathrm{~m}$ apart, and a divertor leg region of $2 \mathrm{~m}$ is used at each end. Because the toroidal magnetic field at the edge of a spheromak is small compared to the poloidal field, we take the B-field to have only a poloidal component.We assume that the divertor leg regions can be designed to give low-recycling of the hydrogen plasma, perhaps Jy drawing these field lines.into a large dump tank. Thus, the hydrogenic iecycling coetificien at the divertors.is assumed to be $R_{h}=0.25$. At the separatrix" ciensity of the hydrogenic species (a $50 / 50 \%$ mixture of deuterium and tritium) is ake: to be $5 \times 10^{19} \mathrm{~m}^{-3}$ and power into the SOL is taken as $0.6 \times 10^{6} \mathrm{y} / \mathrm{H} / \mathrm{m} \mathrm{m}^{2}$ ir both the ion and electron channels. 'The anomalous radial diffusion coefficients axising from plasma turbulence is $0.33 \mathrm{~m}^{2} / \mathrm{s}$ tor density, and $0.5 \mathrm{~m}^{2} / \mathrm{s}$. for electron ind ion therrnal energiès.

The calculated radial plasma profiles at the outer midplane are shown in Fig. 11. The scale length of the density, $n_{i}$ and electron teiriperature, $T_{e}$, are very similar with a $1 / \mathrm{e}$ value of $0.8 \mathrm{~cm}$. The ion temperature has a characteristic highEmperature tail because the ion parallel the mai conductivity is much lower than that of the electrons. This allows radial diffusion to be substantial. 


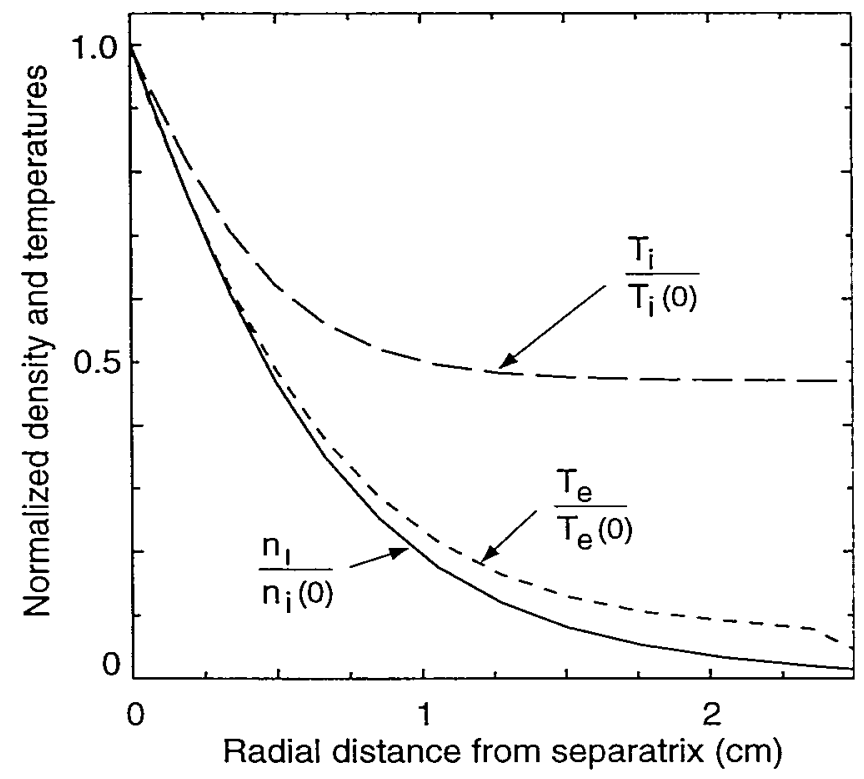

Fig. 11. Radial profiles of ion density, and electron and ion temperatures. Values at the separatrix are $n_{i}(0)=5 \times 10^{19} \mathrm{~m}^{-3}, T_{e}(0)=493 \mathrm{eV}$, and $T_{1}(0)=504 \mathrm{eV}$. The input power from the core is $1.2 \times 10^{6} \mathrm{~W} / \mathrm{m}^{2}$.

The impurity gas coming from the liquid wall is modeled as a uniform flux along the raciai youndary at $\mathrm{r}=6.025 \mathrm{~m}$ (which is $2.5 \mathrm{~cm}$ beyond the separatrix edge) at a terro... ture of $1 \mathrm{eV}$ [14] (Rognlien, 2002?). The impurities have the same : : anoma! : 3 radial diffusion coefficients as the hydrogenic species. The impurity. ions axial $\because: \%$ sire assumed to be reabsorbed mostly into the iiquid with a mall. . recycims coefficient of $R_{\mathrm{imp}}=0.25$. Values of $\mathrm{R}_{\mathrm{mp}}<0.5$ produce very similar results. We cur: ier iwo impurity gas species, lithium and fluorine. Lithium is from. eit.: $: i$. ure lithium wall or from a tin-lithium wall, which evaporates nearly all lithitin. ihe second impurity gas considered is fluorine, which comes from the molte! sclts flibe or flinabe. Because fluorine has the highest charge of the atoms in thesa salts, it has the lowest allowable concentration at the core edge. The resulting impurity concentrations at the core edge are shown in Fig. 12. 


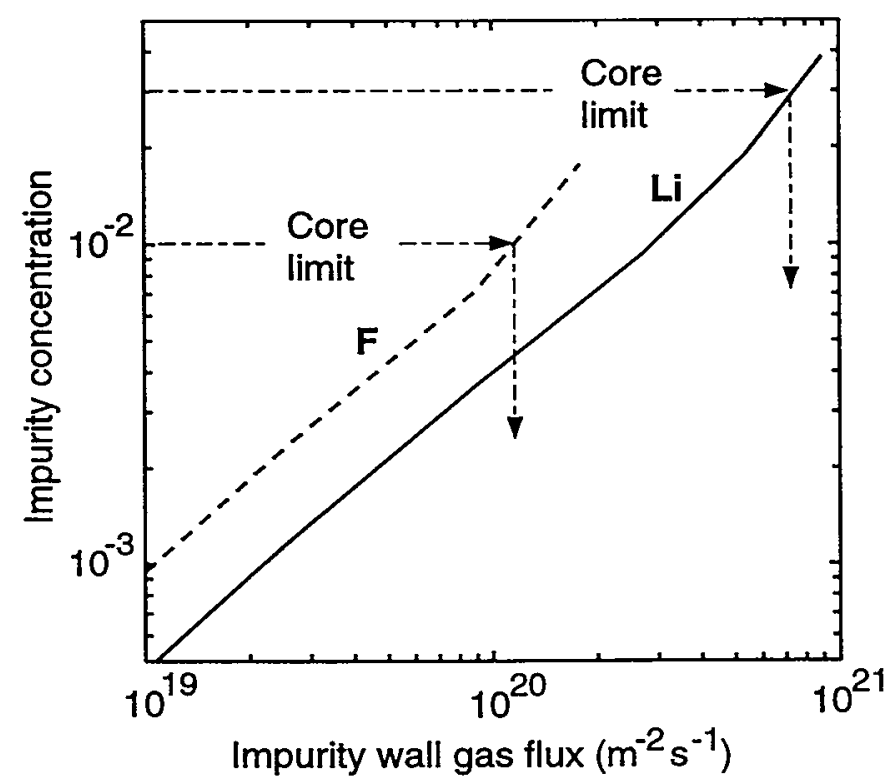

Fig. 12. Concentration of impurities $\left(n_{\text {imp }} / n_{e}\right)$ at the separatrix for various liquid wall impurity gas fluxes distributed uniformly along the wall located $2.5 \mathrm{~cm}$ outside the separatrix.

Data from the vapor pressure of the various liquids versus temperature (see Fig. 5) is then used with a simple model to calculate the vapor flux. Using the limits of flux noted in Fig. 12, we arrive at the following wall temperature limits for three materials:

Table 8.

Maximum surface temperatures of liquid walls

based on acceptable core impurity levels.

\begin{tabular}{|l|l|l|l|}
\hline Material & Lithium & Tin-lithium (80/20) & Flinabe/Flibe \\
\hline Surface Temp. ${ }^{\circ} \mathrm{C}$ & 410 & 630 & 520 \\
\hline
\end{tabular}

The heat flux at the divertor plate is very large in this simple slab model that does not include any expansion of the magnetic flux surfaces shown in Fig. 1 \& 9. For the cases considered here, the parallel heat flux is equal to the poloidal heat flux, because there is no toroidal B-field. As a consequence, the flux is 
approximately $1 \mathrm{GW} / \mathrm{m}^{2}$. The flux expansion of $\sim 10: 1$ will reduce this to $\sim 100$ $\mathrm{MW} / \mathrm{m}^{2}$ This model is double-ended, i.e., double-null. The area of the flux tube before expansion at the $3 \mathrm{~m}$ radius divertor is $2 \pi 3 \mathrm{~m} \times 0.008 \mathrm{~m}=0.151 \mathrm{~m}^{2}$. The escaping power is $454 \mathrm{MW}$ from Table 5 giving $454 \mathrm{MW} / 0.151 \mathrm{~m}^{2} \times 0.5$ (twoended) $=1500 \mathrm{MW} / \mathrm{m}^{2}$. If this flux tube expanded to $12 \mathrm{~mm}$ as discussed earlier the power density would be $1500 \times 8 / 12=1000 \mathrm{MW} / \mathrm{m}^{2}$.

The temperature limit of the divertor surfaces is set by sputtering and evaporation. The latter limit involves the sheath superheat phenomenon as studied for tokamaks $[15,16]$. Based on those studies a rough evaporation-based limit for the present purposes is set by the condition that the evaporating impurity flux is approximately equal to the incoming hydrogen ion flux $[15,16]$. This flux ratio is, "G" = (impurity atom flux)/(hydrogen ion flux). When $G>>1$, (exact limit depending on surface material, flow velocity, and plasma paramters) the sheath collapses and runaway overheating of the surface occurs. For our base-case of a low-recycling divertor, the peak hydrogen ion flux is $2 \times 10^{24}$ $\sin \theta_{\tau}$ particles $/ \mathrm{m}^{2} \mathrm{~s}$, where $\theta_{\tau}$ is the tilt angle that the divertor stream makes with the B-field; $\theta_{\tau}=5^{\circ}$ for the design here. Thus, the rule of $G=1$ implies that the maximum impurity flux is $2 \times 10^{23}$ (particles $/ \mathrm{m}^{2} \mathrm{~s}$ ). From curves of evaporative flux versus surface temperature for different materials shown in Fig. 5, such a flux corresponds to the following temperatures: for $\mathrm{Li}, \mathrm{T}=580{ }^{\circ} \mathrm{C}$; flibe/flinabe, $\mathrm{T}=740 \mathrm{C}$; for $\mathrm{SnLi}, \mathrm{T}=840 \mathrm{C}$, and for $\mathrm{Sn}, \mathrm{T}=1380 \mathrm{C}$. (For lithium, the sputtering limit is likely to be more restrictive). These results can be compared to those predicted on $\mathrm{p} 28$ from heat transfer. For flibe, the evaporative flux predicted from heat transfer with rotating jets was $3.6 \times 10^{23}$ (particles $/ \mathrm{m}^{2} \mathrm{~s}$ ) for the high radiating edge case. Perhaps this case is workable. For the low radiating edge case, the evaporative flux is about two orders of magnitude larger and seems unworkable. Clearly, this subject needs more study. 
For our base-case, the divertor surface is heated by a peak heat flux of $1 \times 10^{3}$ $\sin \theta_{\tau}\left(\mathrm{MW} / \mathrm{m}^{2}\right)$ with a width of $0.6 / \sin \theta_{\tau}(\mathrm{cm})$. The peak temperature of the surface then depends on the conductivity of the liquid, which can be considerably enhanced by any turbulence, especially for low conductivity molten salts flibe and flinabe. Such an analysis is described in section, Liquid Wall Design.

\section{Tritium breeding analysis}

Potential for tritium breeding was assessed in the spheromak shown in Figure 1. The radial blanket consists of $50 \mathrm{~cm}$ thick fast-flowing liquid layer followed by $\sim 50$ thick slow-flowing liquid layer. Flinabe is considered in the present assessment, but a comparison of the adequacy of tritium breeding is also made for Flibe. A design goal is to eliminate the presence of any neutron multiplier (e.g. beryllium) other than that already in the liquid in the radial blankets shown in figure 1 due to its limitation on radiation damage lifetime, and complexity as well as resources concerns. However, the top and bottom blankets could be designed to be dedicated regions to supplement any additional tritium such that tritium self-sufficiency is achieved in the spheromak with a possibility of utilizing beryllium as a multiplier in these regions. Geometrically, the top and bottom regions occupy $\sim 7.5 \%$ each, of the $4 \pi$ of the solid angle, while the radial blanket covers the remainder $(\sim 85 \%)$.

Table 9 shows the options considered in the present assessment. It was shown that lithium- 6 enrichment of $50 \%$ or higher is needed with flinabe, while enrichment of $\sim 25 \%$ is adequate in the flibe case.

Table 10 gives the total tritium breeding ratio (TBR) and the contribution from each blanket when Flinabe is considered as the liquid breeder (design option I). As shown, without beryllium in the top and bottom blankets, the TBR is marginal (TBR 1.05). There is a risk that TBR may fall below unity if more accurate calculations (3-D) and accounting for present nuclear data uncertainties 
are made. The TBR improves upon the utilization of a front Be zone in the top and bottom blankets. In this case, a TBR with comfortable margin is achieved. The TBR is $\sim 1.12$ when $10 \mathrm{~cm}$ thick beryllium zone is used in the top and bottom blankets and is $\sim 1.15$ with $20 \mathrm{~cm}$ thick Be zone.

Table 11 gives the corresponding tritium breeding capability in case the Flibe (25\% Li-6) is used instead. The TBR is larger than with Flinabe by $11-13 \%$ (with Be in top and bottom blankets) and by $15 \%$ (with no Be in top and bottom blankets).

Design option $\mathrm{III}$ (using $\mathrm{Li}-\mathrm{Pb}$ in the top and bottom blankets while Flinabe (or Flibe) is used in the radial blanket) does not offer significant improvement in TBR, as shown in Table 12.

Table 9

Options Considered in Evaluating Tritium Breeding

\begin{tabular}{|l|l|l|l|}
\hline & Option I & Option II & Option III \\
\hline $\begin{array}{l}\text { Radial Blanket } \\
\text { (No Beryllium) }\end{array}$ & $\begin{array}{l}\text { Flinabe } \\
(50 \% \mathrm{Li}-6)\end{array}$ & $\begin{array}{l}\text { Flibe } \\
(25 \% \mathrm{Li}-6)\end{array}$ & Flinabe or Flibe \\
\hline Top Blanket & Flinabe & Flibe & Li-Pb \\
& $(50 \% \mathrm{Li}-6)$ & $(50 \% \mathrm{Li}-6)$ & $(90 \% \mathrm{Li}-6)$ \\
& & & \\
& No Beryllium & No Beryllium & \\
& $10 \mathrm{~cm}$ Be zone & $\mathrm{cm}$ Be zone & \\
& $20 \mathrm{~cm}$ Be Zone & $20 \mathrm{~cm}$ Be Zone & \\
\hline
\end{tabular}


Table 10

Total TBR with Flinabe and Contribution from Various Blankets (Option I)

\begin{tabular}{|c|c|c|}
\hline Blanket Location & TBR & Contribution \\
\hline $\begin{array}{l}\text { Radial Flinabe Wall/Blanket } \\
\text { (No Beryllium) }\end{array}$ & 0.897 & $\begin{array}{l}\sim 85 \%^{1} \\
\sim 80 \%^{2} \\
\sim 78.3 \%^{3}\end{array}$ \\
\hline $\begin{array}{l}\text { Top Flinabe Blanket } \\
\text { No Beryllium } \\
10 \mathrm{~cm} \mathrm{Be} \mathrm{Zone} \\
20 \mathrm{~cm} \mathrm{Be} \mathrm{Zone}\end{array}$ & $\begin{array}{l}0.078 \\
0.111 \\
0.124\end{array}$ & $\begin{array}{l}\sim 7.5 \% \\
\sim 10 \% \\
\sim 10.8 \%\end{array}$ \\
\hline $\begin{array}{l}\text { Bottom Flinabe Blanket } \\
\text { No Beryllium } \\
10 \mathrm{~cm} \mathrm{Be} \mathrm{Zone} \\
20 \mathrm{~cm} \mathrm{Be} \text { Zone }\end{array}$ & $\begin{array}{l}0.078 \\
0.112 \\
0.125\end{array}$ & $\begin{array}{l}\sim 7.5 \% \\
\sim 10 \% \\
\sim 10.9 \%\end{array}$ \\
\hline $\begin{array}{l}\text { Total TBR } \\
\text { No Beryllium } \\
10 \mathrm{~cm} \text { Be Zone } \\
20 \mathrm{~cm} \text { Be Zone }\end{array}$ & $\begin{array}{l}1.05 \\
1.12 \\
1.146\end{array}$ & $\cdot$ \\
\hline
\end{tabular}

1 No Be in Top and Bottom Blankets

210 co Be zone in Top and Bottom Blankets

$320 \mathrm{~cm}$ Be zone in Top and Bottom Blankets 
Table 11

Total TBR with Flibe and Contribution from Various Blankets

(Option II)

\begin{tabular}{|l|l|l|}
\hline Blanket Location & TBR & Contribution \\
\hline Radial Flibe Wall/Blanket & 1.032 & $\sim 85 \%^{1}$ \\
(No Beryllium) & & $\begin{array}{l}\sim 1.5 \%^{2} \\
\sim 80.6 \%^{3}\end{array}$ \\
\hline Top Flibe Blanket & & \\
No Beryllium & 0.089 & $\sim 7.5 \%$ \\
$10 \mathrm{~cm}$ Be Zone & 0.118 & $\sim 9.3 \%$ \\
$20 \mathrm{~cm}$ Be Zone & 0.124 & $\sim 9.7 \%$ \\
\hline Bottom Flibe Blanket & & \\
No Beryllium & 0.089 & $\sim 7.5 \%$ \\
$10 \mathrm{~cm}$ Be Zone & 0.117 & $\sim 9.2 \%$ \\
$20 \mathrm{~cm}$ Be Zone & 0.125 & $\sim 9.7 \%$ \\
\hline Total TBR & & \\
No Beryllium & 1.21 & \\
$10 \mathrm{~cm}$ Be Zone & 1.267 & \\
$20 \mathrm{~cm}$ Be Zone & 1.281 & \\
\hline
\end{tabular}

1 No Be in Top and Bottom Blankets

210 co Be zone in Top and Bottom Blankets

$320 \mathrm{~cm}$ Be zone in Top and Bottom Blankets 
Table 12

TBR with Flinabe or Flibe Breeder in Radial Blanket And $\mathrm{LiPb}$ in Top and Bottom Blankets (Option III)

\begin{tabular}{|l|l|l|}
\hline Blanket Location & TBR & Contribution \\
\hline $\begin{array}{l}\text { Radial Blanket (Flinabe) } \\
\text { Radial Blanket (Flibe) } \\
\text { (No Beryllium) }\end{array}$ & 0.897 & $\sim 80.8 \%$ \\
$(\sim 82.8 \%)$ \\
\hline Top LiPb Blanket & 0.107 & $\sim 9.6 \%^{1}-\sim 8.6 \%^{2}$ \\
\hline Bottom LiPb Blanket & 0.107 & $\sim 9.6 \%^{1}-\sim 8.6 \%^{2}$ \\
\hline $\begin{array}{l}\text { Total TBR: With Flinabe } \\
\text { With Flibe }\end{array}$ & 1.111 & \\
\hline
\end{tabular}

1: With Flinabe in Radial Blanket..... 2: With Flibe in Radial Blanket

\section{Conclusions and discussion}

This study examines a steady-state spheromak with a flowing liquid wall. We are sufficiently encouraged by the results to recommend further work on the concept. However, for flibe, the evaporation from the walls in the high radiating edge case is too high, and for the low radiating edge case, the divertor evaporation is too high. The advantages of the simpler reactor embodiment of the spheromak (without toroidal coils and liquid walls replacing most of the solid first wall) are impressive.

Inconsistencies needing resolution or improved performance are:

- Evaporation from the walls exceed the allowed value for the enhanced radiation case but seems acceptable for the low radiation case. The bremsstrahlung radiation needs to be added to the wall heat load for the flibe case to get a revised film temperature drop estimate. Better estimates of 
optical radiation are needed. The film drop used $0.35 \mathrm{MW} / \mathrm{m}^{2}$ rather than $0.48 \mathrm{MW} / \mathrm{m}^{2}$, as it should have been. The evaporation in the divertor seems possibly acceptable for the high radiating edge case but not for the low radiation edge case.

- The scrape-off layer plasma ( 10 mm) exceeds the magnetic flux layer of 1.5 $\mathrm{mm}$, thus the assumption that most of the exhaust goes to the single null divertor at the bottom is not achieved. The vertical scrape-off layer can exit the machine through the small aperture at the top into a large open tank. This may be a big advantage by lowering the power density in the divertor.

- The gun threading magnetic flux is unusually small (1/1000 time the spheromak flux). Will this be realistically achievable?

- The plasma parameters need to be estimated more accurately with more detailed modeling.

- We should learn how to breed tritium without enriching the lithium and withour adding solid beryllium to the blankets at the top and bottom.

\section{Acknowiedgrnents}

This work is part of the Advanced Power Extraction (APEX) project sponsored by DOE Office of Fusion Energy Science. *Work performed under the auspice of the U.S. Department of Energy by University of California Lawrence Livermore National Laboratory under Contract W-7405-Eng-48.

\section{References}

1. P. M. Bellan, Spheromaks, Imperial College Press, London, 2000.

2. R. L. Hagenson and R. A. Krakowski, Fusion Techn. 8, 1606 (1985). 
3. L. J. Perkins, unpublished work on spheromak reactor designs (1995).

4. T. K. Fowler, D. D. Hua, E. G. Hooper, R. W. Moir and L. D. Pearlstein, Pulsed spheromk fusion reactors," Comments on Plasma Physics and Controlled Fusion, Comments on Modern Physics, Vol 1 Part C 83-98 (1999)

5. P.F. Peterson, UC Berkeley, private communications in a briefing (March 4, 2001).

6. T. K. Fowler and E. B. Hooper, "Advanced Spheromak Fusion Reactor", submitted to the $8^{\text {th }}$ International Conference on Emerging Nuclear Energy Systems (Obninsk, Russia) June 24-28, 1996. Lawrence Livermore National Laboratory Report UCRL-JC-124363, June 19, 1996.

7. M. A. Abdou et al. "On the exploration of innovative concepts for fusion chamber technology," UCLA-ENG-99-206 (1999). Fusion Engineering and Design 54 (2001) 181-247.

8. T. K. Fowler, D. D. Hua and B. W. Stallard, "Simulations of SSPX Sustainment -- Toward a Standard Model tor Spheromaks," UCRL-IDl41998, Jan. 12, 2001.

9. C. W. Barnes, T. R. Jarboe, G. J. Marklin, S. O. Knox and I. Henins, Phys. Fluids B 2, 1871 (1999).

10. S. Cantor, D. S. Hsu, and W. T. Ward, "Vapor Pressures of Fluoride Melts," in Reactor Chem. Div. Ann. Progr. Rept., Oak Ridge National Laboratory, Oak Ridge, Tenn., ORNL-3913, pp. 24-26 (1965). For Flibe.

11. D. R. Olander, G. Fukuda, D. F. Baes, Jr. (2002), “Equilibrium Pressures Over $\mathrm{BeF}_{2}$-LiF (Flibe) Molten Mixtures," Fusion Science and Technology 41(2):141150. 
12. S. Smolentsev, UCLA, private communications, November 13, 2001.

13. S. Smolentsev, M. Abdou, N. Morley, A. Ying, T. Kunugi, "Applications of the

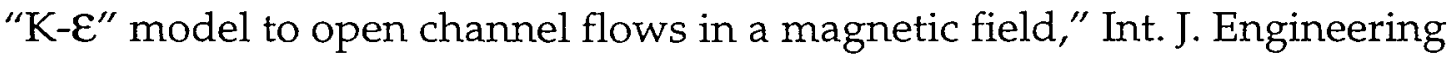
Science, In press (2002).

14. T. D. Rognlien, (2002).

15. J.N. Brooks and D. Naujoks, "Sheath superheat transmission due to redepositon of thermally emitted material," Phys. Plasmas, Vol. 7 (2000) 2565.

16. D. Naujoks and J.N. Brooks, "Combined sheath and thermal analysis of overheated surfaces in fusion devices," J. Nucl. Mater., Vol. 290-293 (2001) 1123. 